Article

\title{
Development of a Biodegradable Microcarrier for the Cultivation of Human Adipose Stem Cells (hASCs) with a Defined Xeno- and Serum-Free Medium
}

\author{
Francesco Muoio $^{1,+}+\mathbb{D}$, Stefano Panella ${ }^{1,+}+\mathbb{D}$, Matias Lindner ${ }^{2,+}$, Valentin Jossen ${ }^{3,+}+\mathbb{D}$, Yves Harder $^{4,5}$, \\ Tiziano Moccetti ${ }^{1}$, Regine Eibl ${ }^{3, \ddagger}$, Michele Müller ${ }^{2, \ddagger}$ and Tiziano Tallone ${ }^{1, *, \ddagger}$ \\ 1 Foundation for Cardiological Research and Education (FCRE), Cardiocentro Ticino Foundation, \\ 6807 Taverne, Switzerland; francesco.muoio@cardiocentro.org (F.M.); \\ stefano.panella@cardiocentro.org (S.P.); tiziano.moccetti@cardiocentro.org (T.M.) \\ 2 Sferalp SA, 6998 Monteggio, Switzerland; mlin@sferalp.com (M.L.); mmul@sferalp.com (M.M.) \\ 3 Institute of Chemistry and Biotechnology, Competence Center of Biochemical Engineering and Cell \\ Cultivation Technique Zurich University of Applied Sciences, 8820 Wädenswil, Switzerland; \\ jose@zhaw.ch (V.J.); eibs@zhaw.ch (R.E.) \\ 4 Department of Plastic, Reconstructive and Aesthetic Surgery, EOC, 6900 Lugano, Switzerland; \\ yves.harder@eoc.ch or yves.harder@usi.ch \\ 5 Faculty of Biomedical Sciences, Università della Svizzera Italiana, 6900 Lugano, Switzerland \\ * Correspondence: tiziano.tallone@cardiocentro.org; Tel.: +41-91-805-38-85 \\ $\dagger$ These authors contributed equally to this study (co-first author). \\ $\ddagger$ These authors supervised this study equally.
}

Citation: Muoio, F.; Panella, S.; Lindner, M.; Jossen, V.; Harder, Y.; Moccetti, T.; Eibl, R.; Müller, M.; Tallone, T. Development of a Biodegradable Microcarrier for the Cultivation of Human Adipose Stem Cells (hASCs) with a Defined Xenoand Serum-Free Medium. Appl. Sci. 2021, 11, 925. https://doi.org/ 10.3390/app11030925

Received: 10 December 2020

Accepted: 16 January 2021

Published: 20 January 2021

Publisher's Note: MDPI stays neutral with regard to jurisdictional claims in published maps and institutional affiliations.

Copyright: (c) 2021 by the authors Licensee MDPI, Basel, Switzerland. This article is an open access article distributed under the terms and conditions of the Creative Commons Attribution (CC BY) license (https:// creativecommons.org/licenses/by/ $4.0 /)$.

\begin{abstract}
Stirred single-use bioreactors in combination with microcarriers (MCs) have established themselves as a technology that has the potential to meet the demands of current and future cell therapeutic markets. However, most of the published processes have been performed using fetal bovine serum (FBS) containing cell culture medium and non-biocompatible MCs. This approach has two significant drawbacks: firstly, the inevitable potential risks associated with the use of FBS for clinical applications; secondly, non-biocompatible MCs have to be removed from the cell suspension before implantation, requiring a step that causes loss of viable cells and adds further costs and complications. This study aimed to develop a new platform based on a chemically defined xenoand serum-free cell culture medium and biodegradable MC that can support the growth of human adipose stem cells (hASCs) while still preserving their undifferentiated status. A specific combination of components and manufacturing parameters resulted in a MC prototype, called "BR44", which delivered the desired functionality. MC BR44 allows the hASCs to stick to its surface and grow in a chemically defined xeno- and serum-free medium (UrSuppe). Although the cells' expansion rate was not as high as with a commercial non-biodegradable standard MC, those cultured on BR44 maintained a better undifferentiated status in both static and dynamic conditions than those cultured on traditional 2D surfaces.
\end{abstract}

Keywords: xeno- and serum-free cell culture medium; UrSuppe; bioresorbable/biodegradable microcarrier (MC); human adipose stem cells (hASCs)

\section{Introduction}

Adipose tissue has become one of the most promising cell sources for regenerative medicine since it is easily accessible. It is an abundant source of adult stem cells that can differentiate along multiple pathways [1-3]. This makes definitively human Adipose Stem Cells (hASCs) a major candidate for tissue engineering applications. They are also increasingly used in plastic and reconstructive surgical procedures, where a shift toward tissue-engineering strategies using stem cells [4-6] is apparent. However, due to the limited number of stem cells that can be extracted from a single donor, one of the major challenges 
for the field of bioengineering is the development of production processes that are both compliant with Good Manufacturing Practice (GMP) guidelines and able to generate a high amount of safe stem cells in a reproducible and cost-effective way [7,8]. This latter aspect, namely the manufacturing costs of cell therapeutics, presents a significant barrier to the widespread implementation of stem cell-based therapies. More specifically, when examining the overall fabrication process, cell expansion represents one of the main cost drivers for cell therapeutics production [8].

One major obstacle is the limited availability of clinical-grade reagents for use in ancillary materials (AMs) [9]. Consequently, it would be essential to develop some of the most crucial AMs needed to manufacture cell therapy products. Therefore, using a defined xeno- and serum-free medium and the development of a biodegradable microcarrier (MC) to produce high numbers of hASCs will represent a step towards the resolution of this issue.

Fetal bovine serum (FBS) is still the most used cell culture medium supplement, although it is an undefined cocktail of numerous growth factors and hormones. This ancillary material is unsafe and risky because it may contain harmful contaminants such as prion, viral, or zoonotic agents [10]. Moreover, human primary progenitor cells grown in FBS-containing media become associated with FBS proteins [11], which may cause immune xenogenic rejection upon autologous transplantation in patients, particularly when multiple doses are required.

Furthermore, tissue (stem) cells usually are never in contact with serum but in contact with the interstitial fluid, which has a lower concentration of proteins than serum and is specific for each tissue or organ due to the unique composition of secreted polypeptides and metabolic molecules [12,13]. This is a situation that we can try to reproduce and mimic by using defined serum-free conditions. Finally, there are also serious ethical concerns about FBS' use regarding its harvesting and production process, without forgetting the risk of adulterated composition and unstable prices.

Biodegradable and biocompatible microspheres are a continuing focus of research for their numerous applications in biomedicine and biotechnology, including immobilization [14,15], affinity chromatography [16,17], drug delivery [18,19], and MCs for the cultivation of anchorage-dependent cells [20-22]. MCs have established themselves as a promising technology for meeting current and future cell therapeutic markets' demands combined with stirred single-use bioreactors. MC technology provides a large culture surface in a small volume for the cost-effective production of adherent cells. It enables reproducible Good Manufacturing Practice (GMP) compliant cell expansions in closed, controlled, and scalable processes [7,23]. A common approach in tissue engineering is to harvest the cells from their growth surface and inject them intravenously. However, for specific applications (such as bone and cartilage repair), there is a need to seed the cells on a scaffold that serves as a substrate and temporary matrix, which can be inserted into the defect to stimulate tissue regeneration. This approach is more time-consuming because it involves three steps: (I) cell expansion in a dedicated system, (II) cell harvesting, and (III) seeding onto a scaffold before implantation. Traditional enzymatic dissociation methods using proteases (i.e., Trypsin) are the most common cell harvesting methods. However, they only result in a 60-70\% cell recovery, depending on the MCs properties. The enzymatic process may also cause reduced cell viability and high apoptotic activity, limiting the transplanted cells' therapeutic efficacy. Therefore, biodegradable MCs are advantageous, as cell harvest or use of new scaffolds is not necessary for cell transfer [24]. In this manner, high cell viability and potency can be maintained.

This feasibility study's product is a porous poly(D,L-lactide-co-glycolide) (PLGA) based MC (called BR44), manufactured as a microsphere with physically embedded porcine gelatin, a natural polymer already approved for clinical use [25]. Due to the adverse effects of FBS in clinical applications $[11,26,27]$, the MC was used with proprietary defined xeno- and serum-free cell culture medium (UrSuppe) suitable for the dynamic cultivation of hASCs in stirred single-use bioreactors. We think that this approach of developing a biodegradable MC combined with a serum-free medium to grow hASCs is very appropriate; 
since it has recently been shown that compatible serum-free media is cell-specific and requires optimization for MC-based dynamic cell culture systems [28]. To our knowledge, only three biodegradable MCs are commercially and readily available: Fujifilm's Cellnest Macroporous Microspheres [29] and the classical Cultisphere G [30] and Cultiphere S [31], while a few examples of resorbable MCs, produced using various techniques and starting materials, including their properties and optimal cultivation conditions, can be found in the scientific literature [7,8,32-35] (see also Table S1 in the Supplementary Material). Hence, we realized that studies combining human stem cells from adipose tissue, biodegradable MCs, a defined xeno- and serum-free medium, and dynamic cell culture conditions are scarce. This study aimed to verify whether the biodegradable MC BR44, together with the defined xeno- and serum-free medium UrSuppe, are appropriate AMs to cultivate adult stem cells. The ASC52telo cell line was used for this feasibility study to expedite and facilitate experimentation. This cell line was generated using hTERT-immortalized cells extracted from human subcutaneous fat and shown to carefully reproduce most of the typical characteristics of primary hASC [36], presenting an ideal cell line for platform validation. In addition to the characterization and comparison of cell growth behavior, special emphasis was also placed on critical cell quality attributes (CQAs). We, therefore, believe that this study can contribute to the development of new protocols for the largescale manufacture of hASCs and lead to a bioreactor-based manufacturing system for the preparation of cell-based therapeutics.

\section{Materials and Methods}

\subsection{Production of Microcarrier Prototypes}

MCs were manufactured through the water in oil in water $\left(\mathrm{W}_{1} / \mathrm{O} / \mathrm{W}_{2}\right)$ double emulsion solvent evaporation method with a foaming agent, according to a modified version of the process defined by Kim et al. [25] to obtain a functionalized MC surface with hydrophilic components (e.g., gelatin). MCs surface functionalization is crucial since the cell culture will be conducted in a defined xeno- and serum-free medium. The cells cannot properly attach to nude MCs (data not shown). Initially, a double emulsion volume of $310.5 \mathrm{~mL}$ was used before scaled-up to a final manufacturing process volume of $2066 \mathrm{~mL}$. All the further development efforts to optimize the parameters were conducted using this final volume.

Poly(D,L-lactide-co-glycolide) (PLGA) (lactide:glycolide ratio 50:50), Purasorb PDLG 5002 (Mw $17 \mathrm{KDa}$ ), Purasorb PDLG 5004 (Mw 44 KDa), Purasorb PDLG 5010 (Mw 153 KDa), Purasorb PLC 7015 and Purasorb PLC 9517 (copolymer of L-lactide and $\varepsilon$-caprolactone) were purchased from Corbion Purac. PLGA with Mw 7 KDa (5050 DLG 1A) was purchased from Evonik. Polycaprolactones (PCL) with Mw $14 \mathrm{KDa}$ and Mw $80 \mathrm{KDa}$ were purchased from Sigma-Aldrich. Polyvinyl alcohol (PVA, 87-89\% hydrolyzed, Mw $31 \mathrm{KDa}$ ) and methylene chloride were purchased from Merck. The bovine and porcine gelatine was a generous gift from Italgelatine (Santa Vittoria d'Alba, Italy), and ammonium hydrogen carbonate was purchased from Applichem.

Several of the manufacturing process parameters that affect different MC characteristics were analyzed. The parameters that were evaluated and mainly affected MCs morphology are as follows: (I) starting polymer raw material, (II) gas foaming agent $\left(\mathrm{NH}_{4} \mathrm{HCO}_{3}\right)$ concentration, (III) PVA concentration, and (IV) polymer concentration in the hydrophobic phase $(\mathrm{O})$, and $(\mathrm{V})$ primary emulsion $\left(\mathrm{W}_{1} / \mathrm{O}\right)$ and secondary emulsion $\left(\mathrm{W}_{1} / \mathrm{O} / \mathrm{W}_{2}\right)$ stirring speeds, which affect the MCs PSD. Furthermore, surface functionalization was attempted using: collagen peptides and gelatin from different sources (fish, bovine, and porcine). Of course, changes in morphology might lead to a consequent change in PSD. Different functionalization molecules also lead to morphological and particle dimension changes, thus creating interconnections between the different characteristics. (I) Several polymers that have biodegradability and resorbability features and are FDA approved were evaluated. The three main polymers tested were: PLGA (50:50 lactic acid/glycolic acid ratio) with different molecular weights $(7 \mathrm{KDa}, 17 \mathrm{KDa}, 44 \mathrm{KDa}$, and $153 \mathrm{KDa})$, PCL (14 KDa 
and $80 \mathrm{KDa}$ ), and two copolymers of lactic acid and caprolactone with different monomer compositions. Specifically, PLC 7015 (30\% caprolactone and 70\% lactic acid) and PLC 9517 (5\% caprolactone and 95\% lactic acid) were used. In general, PCL and both PLC (7015 and 9517) tend to be less prone to porous formation during MC manufacturing processes, while PLGA tends to form perfectly porous structures (Figure 1). This tendency to form a porous surface is reduced when the polymer's molecular weight increases, independently from the used material (PLGA or PCL). For identical foaming agent concentrations, a higher polymer molecular weight results in a less porous surface (data not shown). Based on this understanding, PLGA with a molecular weight of $17 \mathrm{KDa}$ was selected. (II) The gas foaming agent utilized was $\mathrm{NH}_{4} \mathrm{HCO}_{3}$. This was included in the aqueous phase of the primary emulsion and spontaneously produced ammonia and carbon dioxide gas bubbles during solvent evaporation. This phenomenon resulted in the formation of open pores in the interior region and the MC's surface. As already shown by Kim et al. [25], increasing the gas foaming agent's concentration increases the pores' number and size. Concentrations ranging from $0 \%$ to $15 \% w / w$ in $\mathrm{W}_{1}$ were tested, ultimately leading to the selection of $0.3 \%$ $w / w$, which provided an optimal open porous structure and an MC density that resulted in sedimentation within an adequate timeframe. (III) Two different PVA concentrations were tested in $\mathrm{W}_{2}: 0.2 \%$ and $1 \%$. An increase in PVA concentration leads to a reduction in pores on the MC surface and, consequently, to a more spherical bead shape, keeping the PSD comparable (data not shown). The selected PVA concentration was $0.2 \% w / w$ in $\mathrm{W}_{2}$. (IV) The standard polymer concentration in the hydrophobic phase of the primary emulsion, according to our protocol, was $4.3 \% w / w$. An increase in polymer concentration to $8.6 \%$ $w / w$ led to a reduction in porosity and maintained a more spherical MC shape, suggesting that an adjustment in gas foaming agent concentration will be required to maintain the morphological characteristics of the lower polymer concentration. This approach will be followed whenever the manufacturing process needs to be scaled up. (V) The stirring of the primary emulsion was performed by a magnetic bar. At low stirring speed, the MCs are small, and they do not present the effects of the gas foaming agent. High mixing power rates are required to stabilize the emulsion and obtain the desired bead morphology and dimension. In general terms, a stable primary emulsion results in a more homogeneous MC preparation. In the absence of the gas foaming agent, the incorporation of air bubbles in the primary emulsion leads to the formation of open porous MCs in the interior region. The final stirring speed of $W_{1} / O$ was $1400 \mathrm{rpm}$. In terms of $W_{2}$, a higher overhead stirrer speed results in smaller MCs since the size of the $W_{1} / O$ droplet is reduced by the introduced energy. Therefore, the selected speed was $700 \mathrm{rpm}$ during the secondary emulsion formation phase and $300 \mathrm{rpm}$ during the overnight evaporation step. During the manufacturing process, several functionalizations were evaluated to develop a ready to use a product that does not require post-manufacturing coatings. Different protein sources were evaluated, including gelatin and collagen peptides of different animal origins. The difference between gelatin and collagen peptides is mainly the amino acid chains' length, with the collagen peptides having shorter chains. This difference affects their solubility and ability to form a gel at room temperature. The presence of these proteins positively affects the stability of the primary emulsion. Gelatin was successfully incorporated into the MC matrix and surface. More difficulties were encountered with collagen peptides, as demonstrated by Bicinchoninic Acid (BCA) testing on the final products (data not shown). The difference in water solubility at different temperatures and the smaller molecular weight might explain the difficulty in incorporating the collagen peptides into the polymeric matrix. Bovine and porcine gelatin provide comparable results in morphology and microcarrier PSD; however, porcine gelatin is more acceptable for the medical regulatory authorities since it avoids BSE-related issues, leading to porcine gelatin being the gelatin of choice. 

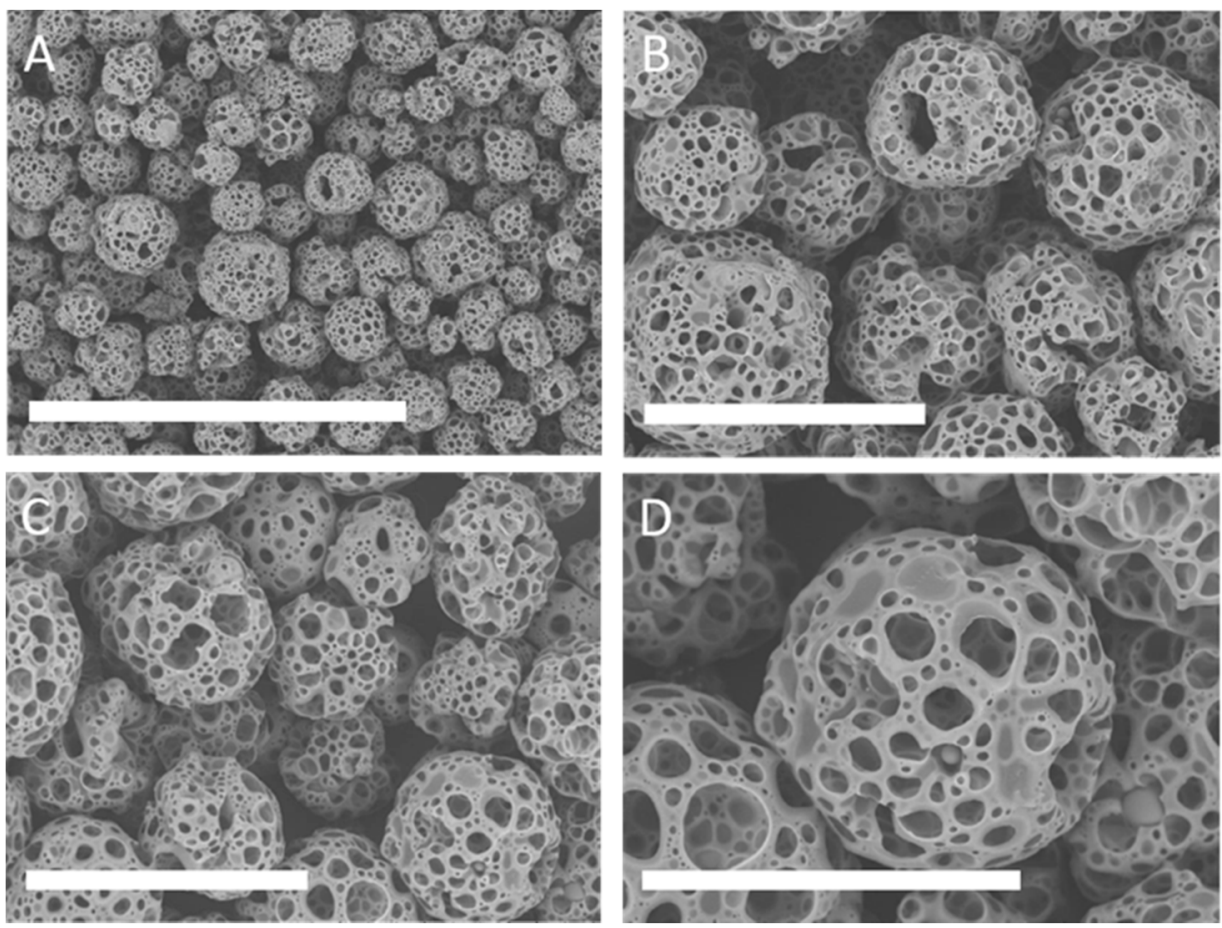

Figure 1. Scanning electron microscopy (SEM) microphotographs to show the morphology of the BR44 microcarrier (MC). SEM examination of this carrier showed good uniformity of shapes and sizes. BR44 is highly porous. Fold magnification: (A): $100 \times$, scale bar $1 \mathrm{~mm}(\mathbf{B}, \mathbf{C}): 250 \times$, scale bar $300 \mu \mathrm{m}$ (D): $500 \times$, scale bar $200 \mu \mathrm{m}$.

\subsection{Cell and Culture Medium}

\subsubsection{Culture Medium}

The cells used in the experiments were exclusively cultivated using a proprietary defined xeno- and serum-free cell culture medium (UrSuppe), which was specifically formulated to grow human adipose stem cells (hASCs). UrSuppe was developed by testing the growth of hASCs with different basal media, several animal-free supplements, and a selected number of recombinant growth factors. Therefore, it only contains defined molecules, some recombinant human growth factors, and injectable human albumin in the $\mu \mathrm{g}$ range.

\subsubsection{Cell Expansion and Subculture}

All of the described experiments were performed with ASC52telo cells (ATCC SCR400TM). This human adipose stem cell line was immortalized by ectopic expression of the human Telomerase's catalytic subunit (hTERT) [36]. The cells were seeded at a density of 5000-10,000 cells $/ \mathrm{cm}^{2}$ in a T25 flask (TPP, Techno Plastic Products AG, Trasadingen, Switzerland) and incubated in a standard cell culture incubator $\left(37^{\circ} \mathrm{C}, 5 \% \mathrm{CO}_{2}, \mathrm{rH}>80 \%\right)$ in UrSuppe. The medium was replaced every two days until the cells had reached between $80-90 \%$ confluency. Cells were detached with TrypLE Select (Life Technologies, Thermo Fisher Scientific, Waltham, MA, USA) for 2 min at $37^{\circ} \mathrm{C}$, then washed with PBS supplemented with $1 \%$ human albumin (CSL Behring AG, Bern, Switzerland) and pelleted by centrifugation at $400 \times g$ for $5 \mathrm{~min}$. After discarding the supernatant, the cells were resuspended in UrSuppe and passaged or used for tests with the MC prototypes.

\subsection{Characterization and Selection of the Prototype MCs}

2.3.1. Selection of a Well-Performing Biodegradable MC Prototype: Cell Attachment Studies

MCs were tested for their ability to allow the attachment of ASC52telo cells under xenoand serum-free conditions. To have a "gold standard" and positive control to compare our MCs' performance, we choose ProNectin-F MCs (Pall SoloHill, Port Washington, NY, 
USA). This commercial MC performed very well with our defined and other cell culture media [37]. The test used for this screening was as follows: (A) Preparation of the cells: The cells were detached from the cell culture vessel with TrypLE Select (after 2 min, incubation at $37^{\circ} \mathrm{C}$ ), washed with PBS supplemented with $1 \%$ human albumin, counted with Trypan Blue (Life Technologies, Thermo Fisher Scientific, Waltham, MA, USA) and resuspended in a culture medium at a concentration of 70,000 cells in $250 \mu \mathrm{L}$; (B) Preparation of the positive control MC: ProNectin-F MCs (PNF) were incubated in cell culture medium for one hour at $37^{\circ} \mathrm{C}$ under agitation; C) Preparation of the test MCs: The different biodegradable MC prototypes manufactured by Sferalp were washed in PBS and then incubated in UrSuppe for $60 \mathrm{~min}$ at $37^{\circ} \mathrm{C}$ under agitation. Immediately before the tests, the MCs were resuspended in $250 \mu \mathrm{L}$ of fresh UrSuppe medium, resulting in a theoretical grow surface of $2.5 \mathrm{~cm}^{2}$ for the ProNectin-F MC and $1 \mathrm{~cm}^{2}$ for the BR44 prototypes. All of the screening tests were performed on low cell attachment plates (Ultra-Low 24 well Multiplate, Corning Inc., Corning, NY, USA). MC suspensions of $250 \mu \mathrm{L}$ were transferred to each well, and the plate was gently mixed to distribute the MCs. Then, $250 \mu \mathrm{L}$ of the ASC52telo cell suspension was added. After gently mixing, the plate was placed in an incubator $\left(37^{\circ} \mathrm{C}, 5 \% \mathrm{CO}_{2}\right)$, and the cells were cultured for seven days. Every two to three days, $50 \%$ of the medium was removed and replaced with fresh, preheated UrSuppe medium. After overnight incubation, it was usually possible to identify the low performing MCs since very few or no cells were attached to the carriers. The non-adherent cells tended to form multiple cellular aggregates (data not shown). Evaluation of the degree of colonization of the tested MCs was performed using phase-contrast microscopy, fluorescent microscopy, and SEM (see below). Of all the combinations of organic and biological polymers, shapes, porosities, and other tested parameters, the best combination that resulted in a carrier promoting cell attachment and proliferation comparable with a commercial product were BR44. Thus, this MC prototype was used for all project-specific experiments

\subsubsection{Dimension of MCs: Particle Size Distribution (PSD) Analysis}

After manufacturing, the MCs were passed through $100 \mu \mathrm{m}$ and $250 \mu \mathrm{m}$ sieves to obtain a MC fraction within this Particle Size Distribution (PSD) range. The PSD was measured using a Sympatec HELOS Laser equipped with a cuvette dispersing system in distilled water at room temperature (magnetic stirring required at $800 \mathrm{rpm}$ ). An R5 lens was used (size range 4.5 to $875 \mu \mathrm{m}$ ), and the trigger conditions were set as follows: timebase: $1000 \mathrm{~ms}$, start: Ch. $10 \geq 3$, valid: $10 \% \leq$ Ch. $10 \leq 25 \%$, duration: $10 \mathrm{~s}$.

\subsubsection{Gelatin Distribution on MC Surface}

According to the manufacturer's instructions, the MCs were labeled with a Mix-nStain $\mathrm{CF}^{\circledR} 633$ Labelling Kit (Biotium Inc., Freemont, CA, USA). This step covalently bonds the CF633 fluorophore to the gelatin. The MCs were subsequently mounted on microscope slides using $85 \%$ glycerol solution (Hänseler AG, Herisau, Switzerland). Images were acquired using a red laser $(633 \mathrm{~nm})$ on a confocal microscope Nikon C2 (Nikon, Minato, Tokyo, Japan).

\subsection{Bioengineering Investigations}

\subsubsection{Sedimentation Velocity of MCs}

The sedimentation velocities of the best performing MC, BR44 MC prototype, and the commercially available ProNectin-F MC were measured by imaged-based analysis. For this purpose, $3 \mu \mathrm{L}$ of the respective MC suspension was added dropwise to a cylindrical flow chamber filled with UrSuppe cell culture medium. The sedimentation process for the different MC types was recorded with a high definition camera $(1920 \times 1080$ pixels, $29 \mathrm{fps})$, and the individual images were analyzed using Matlab (MathWorks, Natick, MA, USA) and ImageJ (open source software) to track the single MC particles and to calculate the sedimentation velocity distribution for each MC type. The images were only analyzed 
in the lower part of the flow chamber to measure individual MC particles' maximum sedimentation velocities.

\subsubsection{Determination of $N_{s 1 u}$ and $N_{s 1}$ Suspension Criteria}

The suspension criteria $\left(N_{s 1}, N_{s 1 u}\right)$ were determined for the BR44 MC prototype and the commercially available ProNectin-F MC. The method defined by Kaiser et al. [38] and Jossen et al. [39] for determining the suspension criteria in a $125 \mathrm{~mL}$ Corning spinner flask was used. In brief, the $N_{s 1}\left(N_{j s}\right.$, or just suspended) suspension criterion was defined as the impeller speed required to just entirely suspend the MCs in the spinner flask [40]. $N_{s 1 u}$ described the suspension state at which some of the MCs were still in contact with the reactor bottom, but none of them were at rest [41]. The suspension experiments were carried out for MC concentrations that corresponded to theoretical growth surfaces of $180 \mathrm{~cm}^{2}$ and $360 \mathrm{~cm}^{2}$. While the impeller was in motion, the suspension state was recorded by a digital camera, and the recordings were subsequently visually evaluated. Optical accessibility to the spinner flask bottom was improved by a mirror that was placed below the flask.

\subsubsection{Stability of $B R 44$ under Stirred Conditions}

The BR44 MC prototype's stability was investigated under stirred conditions $\left(\mathrm{N}=N_{s 1 u}\right)$ for up to 14 days in a Corning spinner flask $(100 \mathrm{~mL})$ without cells. For this purpose, MCs that corresponded to a theoretical specific growth surface of $360 \mathrm{~cm}^{2}$ were resuspended in UrSuppe medium and transferred to the spinner flask, which was incubated in a standard cell culture incubator $\left(5 \% \mathrm{CO}_{2}, 80 \% \mathrm{rH}\right)$. Daily samples were taken and examined microscopically (EVOS fl auto 2, Thermo Fisher Scientific) to monitor the stability of the BR44 MCs and to detect morphological changes. Based on the microscopic images, the BR44 MC prototype's size distribution was determined on day zero and day 14 using ImageJ analysis software.

\subsection{Cultivation Studies}

\subsubsection{Cell Adhesion on the MCs: Nuclei Staining with DAPI}

Nuclei staining is a reliable approach for assessing cell density during the MC-based culture of adherent cells. After two and four days of growth, MCs with attached cells were treated with a fixing solution ( $2 \%$ formaldehyde, $0.2 \%$ glutaraldehyde in PBS, SigmaAldrich Inc., St. Louis, MO, USA) for 30 min on ice, washed two times with PBS, and then resuspended in $500 \mathrm{nM}$ DAPI (4',6-diamidino-2-phenylindole) solution (Sigma-Aldrich Inc., St. Louis, MO, USA) for $20 \mathrm{~min}$ at room temperature in the dark. After two additional washing steps, the MC-cell aggregates were resuspended in 85\% Glycerol solution and mounted for microscopic analysis on $\mu$-Dish (Ibidi, Gräfelfing, Germany). Images were acquired using an inverted fluorescence microscope (UV laser $405 \mathrm{~nm}$ ) Nikon Eclipse Ti (Nikon, Minato, Tokyo, Japan).

\subsubsection{Cell Adhesion on MC Prototypes; SEM Analysis}

After two and four days of growth, MCs with cells were fixed in 3\% glutaraldehyde solution for $30 \mathrm{~min}$ on ice, washed twice, and then resuspended in distilled H20. The samples were then dried directly on a metal specimen stub at room temperature for $3 \mathrm{~h}$. Once completely dry, the samples were coated with gold/palladium particles in a Mini Sputter Coater at $18 \mathrm{~mA}$ for $60 \mathrm{~s}$. SEM analysis was performed with a Hitachi TM3030 microscope at $15 \mathrm{KV}$.

\subsubsection{Nuclei Count and Evaluation of Cell Proliferation}

Cell attachment and proliferation were determined by taking periodic samples. MCs covered with cells were transferred into $5 \mathrm{~mL}$ tubes (Eppendorf, Hamburg, Germany) and quickly spun down. After discarding the supernatant, the MCs were resuspended in Lysis and Nuclei Extraction Buffer (LNEB: 2\% Triton-X, 0.2 M Citric Acid), which lyses the cells 
without altering the MCs. This suspension was then filtered through a micro-strainer with a $40 \mu \mathrm{m}$ mesh diameter (PluriSelect Life Science UG, Leipzig, Germany) to separate the nuclei from the MCs. After another centrifugation step at $800 \times g$ for $5 \mathrm{~min}$, the cell nuclei were resuspended in $100 \mu \mathrm{L}$ of LNEB buffer and stained with $1.25 \mathrm{ng} / \mu \mathrm{L}$ of 7 -AAD. Cell nuclei were acquired using a Cytoflex flow cytometer (Beckman Coulter Inc., Pasadena, CA, USA), and the data were an alyzed with Kaluza software (Beckman Coulter Inc., Pasadena, CA, USA).

Cell nuclei were gated based on Forward Scatter, Side Scatter, and 7-AAD fluorescence. The linear scale of 7-AAD fluorescence was used to discriminate between cells in G1-S-G2 phases. For more details, see Supplementary Material (Evaluation of cell proliferation, Figure S1).

\subsubsection{Cellular Detachment}

The cell-MC aggregates were transferred to a $5 \mathrm{~mL}$ tube and incubated for $10 \mathrm{~min}$ at $37^{\circ} \mathrm{C}$ with TrypLE Select (Life Technologies ThermoFisher Scientific, Waltham, MA, USA) under agitation; after dissociation, the hASCs were washed with PBS supplemented with human albumin and filtered through a $40 \mu \mathrm{m}$ microtube mesh to separate the cells from the MCs. Both the filter and the wells were washed several times to maximize cellular recovery. The cell suspension was pelleted by centrifuging at $400 \times g$ for $5 \mathrm{~min}$ and then resuspended in fluorescence activated cell sorting (FACS) buffer (PBS supplemented with 1\% albumin and $50 \mathrm{ng} / \mu \mathrm{L}$ human immunoglobulins, Privigen Immunoglobulin, CSL Behring AG, Bern, Switzerland) for flow cytometry analysis, or in Extraction Buffer (7 M Urea, 1\% SDS, $0.35 \mathrm{M} \mathrm{NaCl}$, Sigma-Aldrich Inc., St. Louis, MO, USA) for RT-qPCR analysis.

\subsubsection{Proof-of-Concept Spinner Cultivation}

The ASC52telo cells were used for the proof-of-concept cultivation using the BR44 prototype and the ProNectin-F MCs in a $125 \mathrm{~mL}$ Corning spinner flask. MCs that corresponded to a theoretical growth surface of $360 \mathrm{~cm}^{2}$ were used $(B R 44=1.01 \mathrm{~g}$, ProNectin-F $=1.0 \mathrm{~g})$ to innoculate each spinner flask. The growth surface per spinner flask was defined based on previous investigations by Schirmaier et al. [42]. For each condition, one spinner flask was inoculated with the ASC52telo cells and cultivated for nine days at $37{ }^{\circ} \mathrm{C}$, with $5 \%$ $\mathrm{CO}_{2}$, and $80 \%$ humidity. Both spinner flasks were inoculated with the same inoculum (P24, PDL35), which was prepared using T75 flask cultures $\left(10,000\right.$ cells $\left./ \mathrm{cm}^{2}\right)$. In addition to the spinner flask cultures, the ASC52telo cells were also expanded in a T75-flask as a static control. Before inoculation, both MC suspensions were equilibrated for $4 \mathrm{~h}$ in a cell culture incubator in UrSuppe. Post inoculation, no agitation was performed for $24 \mathrm{~h}$ to support cell attachment on the MC surface. After the cell attachment phase, the impeller was adjusted according to the MC-dependent $N_{s 1 u}$ criterion. On days four and eight, partial medium exchanges of $50 \%$ were performed. For this purpose, the impellers were switched off, and the MCs were allowed to settle. Fifty percent of the spinner flasks' working volume was replaced with fresh preheated UrSuppe medium, and the impellers were restarted.

\subsubsection{Spinner Cultivation: Analyses}

Off-line samples were taken daily to measure the substrate $(G l c)$ and metabolite (Lac, Amn) concentrations using a BioProfile 100Plus (Nova Biomedical, Waltham, MA, USA). After the cells had detached from the MC surface (15 min TrypLE Select), the cells were counted using a NucleoCounter NC-200 (ChemoMetec, Denmark). Based on the regular measurements of cell density and substrate/metabolite concentration, growth-dependent parameters Equations (1)-(6) were calculated:

(I) Specific growth rate $\mu$ (Equation (1))

$$
\mu=\frac{\ln \left(X_{A}(t)\right)-\ln \left(X_{A}(0)\right)}{\Delta t}
$$


where $\mu$ is the net specific growth rate. $X_{A}(t)$ and $X_{A}(0)$ are the cell numbers at the end and the beginning of the exponential growth phase, respectively, and $t$ is the time.

(II) Doubling time $t_{d}$ (Equation (2))

$$
t_{d}=\frac{\ln (2)}{\mu}
$$

where $t_{d}$ is the doubling time, $\ln (2)$ the binary logarithm of 2 , and $\mu$ the specific growth rate.

(III) Population Doubling Level PDL (Equation (3))

$$
P D L=\frac{1}{\log (2)} \cdot \log \left(\frac{X_{A}(t)}{X_{A}(0)}\right)
$$

where $P D L$ is the number of population doublings, and $X_{A}(0)$ and $X_{A}(t)$ are the cell numbers at the beginning and the end of the cultivation, respectively.

(IV) Expansion factor EF (Equation (4))

$$
E F=\frac{X_{A}\left(t_{\max }\right)}{X_{A}(t=0)}
$$

where $E F$ is the expansion factor, $X_{A}\left(t_{\max }\right)$ is the maximum cell number, and $X_{A}(t=0)$ is the inoculated cell number.

(V) Lactate yield from glucose $Y_{\text {Lac / Glc }}$ (Equation (5))

$$
Y_{L a c / G l c}=\frac{\Delta L a c}{\Delta G l c}
$$

where $Y_{L a c / G l c}$ is the lactate yield from glucose, $\Delta L a c$ is the lactate production over a specific time period and $\Delta G l c$ is the glucose consumption over the same time period (the exponential growth phase).

(VI) Specific metabolite flux $q_{\text {met }}$ (Equation (6))

$$
q_{m e t}=\left(\frac{\mu}{X_{A}(t)}\right)\left(\frac{C_{m e t}(t)-C_{m e t}(0)}{e^{\mu t}-1}\right)
$$

where $q_{m e t}$ is the net specific metabolite consumption or production rate (for Glc, Lac, $A m n), \mu$ is the specific cell growth rate, $X_{A}(t)$ is the cell number at the end of the exponential growth phase, $C_{\text {met }}(t)$ and $C_{\text {met }}(0)$ are the metabolite concentrations at the end and the beginning of the exponential growth phase, respectively, and $t$ is the time.

\subsection{Cell Analytics}

\subsubsection{Flow Cytometry Analysis}

Reagents: Each test contained different mixtures of the following antibodies: CD73FITC, CD105-PE (BioLegend, San Diego, CA, USA), CD34-PE, CD36-APC, CD90-FITC, CD146-PE (Miltenyi Biotec, Bergisch, Germany), CD61-PE (Beckman Coulter Inc., Pasadena, CA, USA), CD15-FITC, and 7-AAD (Becton Dickinson, Franklin Lakes, NJ, USA). All of the antibodies were titrated to optimize the signal-to-noise ratio and used at a $50 \mathrm{ng} /$ test concentration. The same final concentrations of the isotype controls and the specific mAbs were used. Staining procedure: 50,000 cells (in $100 \mu \mathrm{L}$ FACS buffer) were pipetted into a well, gently mixed with the appropriate antibody combination, and incubated in the dark for $15 \mathrm{~min}$ at room temperature. Finally, the sample was diluted with $100 \mu \mathrm{L}$ FACS buffer before the cells were acquired. Instrument Setup and Sample Acquisition: Cells were acquired using a Cytoflex flow cytometer (Beckman Coulter Inc., Pasadena, CA, USA) and analyzed using Kaluza software (Beckman Coulter Inc., Pasadena, CA, USA). No statistical and significant tests were performed on marker expression. To determine the fluorochromes' spill-over coefficients, fluorescence compensation was assessed using single stained control particles (VersaComp Antibody Capture Bead Kit, Beckman Coulter) or cells. 
The compensation matrix was determined using the Kaluza software's dedicated function. 7-AAD was used to discriminate between dead and live cells. Flow-check fluorospheres (CytoFLEX Daily QC Fluorosphere, Beckman Coulter) were run periodically to verify optical alignment and fluidics. Detailed information on the antibodies can be found in Supplementary Material Table S2.

\subsubsection{RT-qPCR Analysis}

According to the manufacturer's instructions, RNAs were extracted from cell pellets or MCs covered with cells using the Nucleospin ${ }^{\circledR}$ RNA kit (Macherey-Nagel, Düren, Germany). The kit's purification procedure also includes an on-column digestion step using DNase I. RNA purity and quantity were assessed with the NanoDrop device (Thermo Fisher Scientific, Waltham, USA) total RNA integrity was periodically verified by conventional agarose gel electrophoresis. cDNA was obtained from $400 \mathrm{ng}$ RNA using the GoScriptTM Reverse Transcription System (Promega, Madison, WI, USA), and the protocol can be found in Supplementary Material, Table S3. RT-qPCR of the SOX9, RUNX2, PPARG, PREF1, ZFP423, ZFP521, WISP2, and DKK1 genes was performed using the SsoAdvancedTMUniversal SYBR ${ }^{\circledR}$ Green Supermix kit (Biorad, Hercules, CA, USA) and detected using the CFX Connect system (Biorad, Hercules, CA, USA). RT-qPCR was performed for each gene using $20 \mathrm{ng}$ of cDNA, and ACTB was used as an internal control. Each primer pair product was checked for proper amplification by agarose gel electrophoresis. Only primers that gave rise to single sharp bands of the expected size were used. Primer sequences, temperature, and cycle conditions can be found in Supplementary Material Tables S4 and S5. The data were analyzed using the CFX software to calculate the relative fold gene expression using the formula $2^{-\Delta \Delta \mathrm{Ct}}$. No statistical and significant tests were performed on gene expression.

\subsubsection{Secretome Profiler}

ASC52telo cells were grown in standard cell culture vessels (2D static) or spinner flasks (ProNectin-F and BR44 MC). The cell culture system was analyzed to detect secreted factors. Each conditioned medium was filtered through a $0.22 \mu \mathrm{m}$ syringe mesh (Jet Biofil, Guangzhou, China) to remove cellular debris, then $1 \mathrm{~mL}$ of each supernatant was incubated overnight with a nitrocellulose membrane containing 58 different capture antibodies. The array procedure was carried out according to the instructions provided with the Proteome Profiler Human Adipokine Array Kit (R and D Systems, Minneapolis, MN, USA). Streptavidin conjugated IRDye 800 CW (Li-Cor Corporate, Lincoln, NE, USA) highlighted the secondary biotinylated detection antibodies. The positive signals were detected after scanning the membrane using an Odyssey ${ }^{\circledR}$ CLX Imaging System (Li-Cor Corporate, Lincoln, NE, USA). Data were analyzed using Li-Cor software to calculate signal intensity ratios between the adipokines and the control reference spots.

\section{Results}

3.1. Characterization and Selection of the Prototype MCs

\subsubsection{Shape and Dimensions of the MCs}

More than 50 different MC prototypes were manufactured with different polymeric compositions, different gelatines, and peptides derived from gelatin hydrolyzation were tested in combination with different shapes, sizes, and porosities of microbeads. After founding the best combination that promotes cell attachment and proliferation, we focus on the characterization of the biochemical engineering properties of $B R 44$. It consists of a mixture of poly lactic-co-glycolic acid (PLGA) and porcine gelatin. Scanning electron microscopy (SEM) of the BR44 MC showed good uniformity of shapes and sizes (Figure 1), comparable with standard commercial MCs composed of natural bio-polymers (see Supplementary Material Figures S2 and S3). 
Analytical characterization of MCs represents an important tool for the comparison of prototypes obtained during the screening phase. Figure 2 shows and Table 1 summarizes the biophysical properties of the BR $44 \mathrm{MC}$. The results of the particle size distribution measurements demonstrate the reproducibility of the manufacturing process since the size distribution of the BR44 MCs varied only slightly between the different batches.

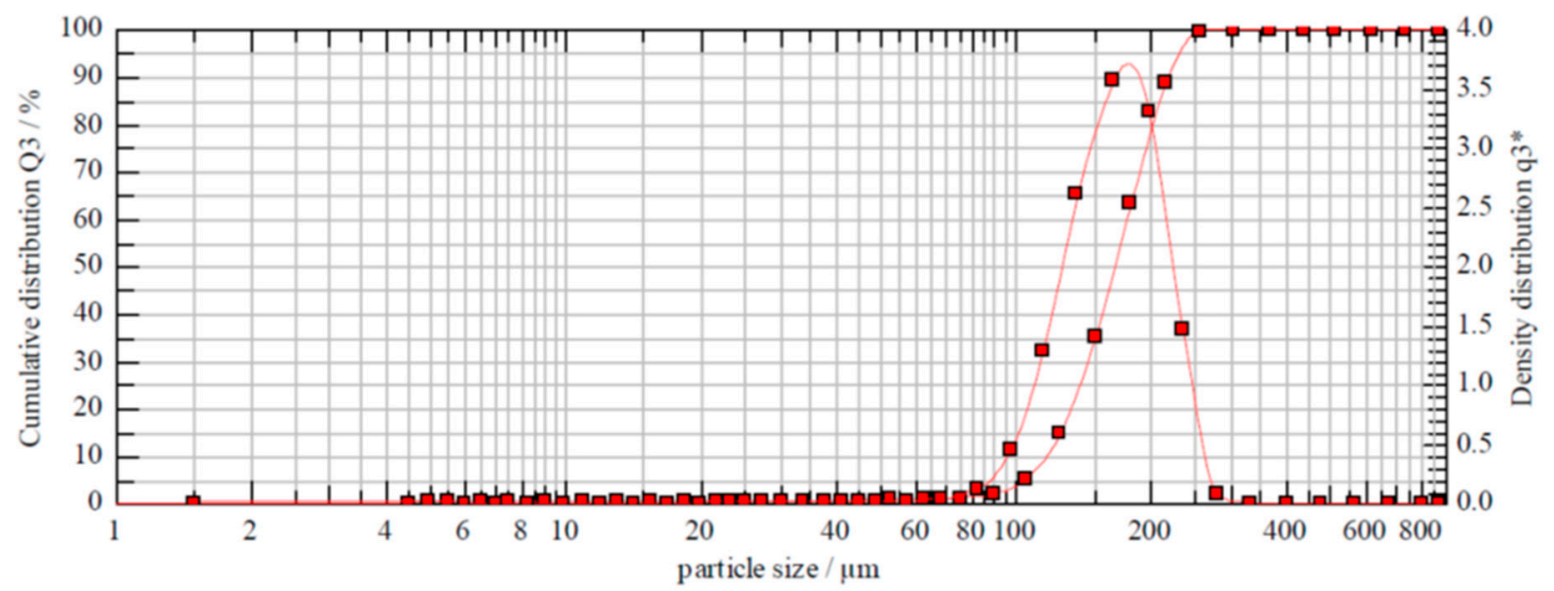

Figure 2. Particle size distribution (PSD) of $B R 44$. The figure shows the cumulative and density distribution of one batch of $B R 44$ as a representative example. $X_{10}=116 \mu \mathrm{m}, X_{50}=166 \mu \mathrm{m}, X_{90}=220 \mu \mathrm{m}$.

Table 1. Biophysical properties of $B R 44$. Data represent the mean of six different batches of $B R 44$.

\begin{tabular}{|c|c|c|c|c|}
\hline \multirow{2}{*}{ Concentration $(\mathrm{g} / \mathrm{mL})$} & \multicolumn{3}{|c|}{ Particle Size Distribution (PSD) $(\mu \mathrm{m})$} & \multirow{2}{*}{ Theoretical Surface $\left(\mathrm{cm}^{2} / \mathrm{g}\right)$} \\
\hline & $X_{10}$ & $X_{50}$ & $X_{90}$ & \\
\hline $0.034 \pm 0.0002$ & $116.76 \pm 1.93$ & $166.41 \pm 3.44$ & $221.55 \pm 3.56$ & $355.77 \pm 6.04$ \\
\hline
\end{tabular}

\subsubsection{Proof of Homogeneous Gelatin Distribution on MC Surfaces}

Gelatin is essential for cell attachment in a serum-free medium. Therefore, it was crucial to establish how the porcine gelatin proteins are distributed on the surface of the $\mathrm{MC}$ prototype BR44. For this purpose, the CF633 fluorescent dye was used to conjugate the proteins to check their presence and distribution (porcine gelatin) on the surface of $B R 44$ (Figures 3 and 4). The BR13C MC prototype, which does not contain proteins and is made of pure PLGA (see Supplementary Material Figure S4), was chosen as a negative control for this test. Various commercial MCs either with surfaces (peptides or primary amines) that react to the CF633 dye or with a protein coating (Collagen I, Fibronectin, Gelatin) on their outer shell were used as a positive control. The analysis of these MCs was also intriguing because it demonstrated how some companies solved the problem by coating their microspheres' surface layer to allow adhesion and cell growth. The results obtained with these commercial MCs are shown in Supplementary Material Figure S5. The CF633 fluorescent dye (molecular weight $\sim 820 \mathrm{~g} / \mathrm{mol}$ ) reacts with the accessible primary amines of proteins, highlighting their presence and distribution on the MC BR44 prototype's surface. As shown in Figure 3, the porcine gelatin proteins are homogeneously distributed and present at a high density on the carrier's surface. Furthermore, the images demonstrate and confirm that this $\mathrm{MC}$ is also highly porous on the inside. 

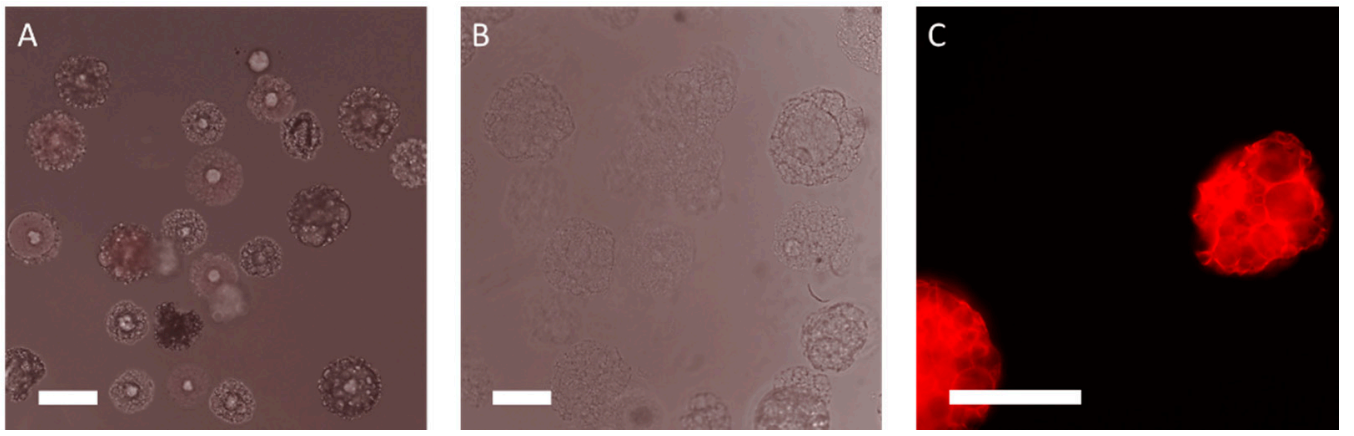

Figure 3. Fluorescent microphotographs of the MCs prototypes. (A) BR13 (negative control): poly(D,Llactide-co-glycolide) (PLGA) MCs without gelatin after reaction with the CF633 dye, exposure time: $400 \mathrm{~ms}$, no fluorescence in the red channel. Magnification 100×, scale bar $150 \mu \mathrm{m}$. (B) BR44 no staining with the CF633 dye (negative control), no fluorescence in the red channel. Magnification $100 \times$, scale bar $150 \mu \mathrm{m}$. (C) BR44 reaction with the CF633 dye, exposure time: 400 ms. Magnification $200 \times$, scale bar $150 \mu \mathrm{m}$.
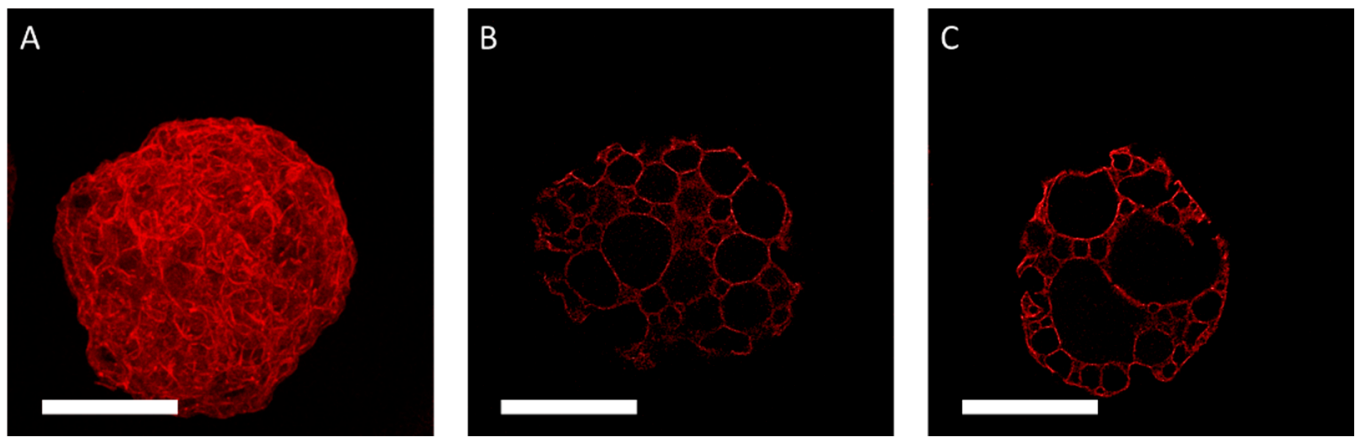

Figure 4. Confocal microscopy analysis of the prototype BR44 MC stained with the fluorescent CF633 dye. (A). 2D convolution. (B,C). Microphotographs of two different sections. Magnification 400×, scale bar $100 \mu \mathrm{m}$.

\subsection{Bioengineering Investigations}

\subsubsection{Sedimentation Velocity Distribution of BR44 MC}

The sedimentation velocities of the $B R 44$ prototype ranged between $0.13 \mathrm{~mm} / \mathrm{s}$ and $2.2 \mathrm{~mm} / \mathrm{s}$, whereas the values for the ProNectin-F MC ranged between $0.38 \mathrm{~mm} / \mathrm{s}$ and $3.57 \mathrm{~mm} / \mathrm{s}$. Thus, the mean sedimentation velocities of the $B R 44$ prototype $(0.63 \mathrm{~mm} / \mathrm{s})$ were up to $56 \%$ lower than those measured for the ProNectin-F MC $(1.46 \mathrm{~mm} / \mathrm{s})$.

\subsubsection{Suspension Studies with the BR44 and ProNectin-F MCs}

Different BR44 MC suspension states are represented in Figure 5 for the Corning spinner flask. As can be seen from the images, different suspension states can be detected: (I) transport of the MCs to the vessel center and the formation of a clear outer zone, (II) swirling up of the MCs from the center of the vessel bottom and further reduction of the $\mathrm{MC}$ solid fraction at the reactor bottom, and (III) maintaining the BR44 MCs in suspension $\left(N_{s 1 u}<N<N_{s 1}\right)$. Comparable suspension states were also observed for the ProNectin $\mathrm{F}$ MC. Table 2. shows the results of the suspension studies using the BR44 prototype and the ProNectin-F MC. The impeller speeds determined for $N_{s 1 u}$ were between 75 and $85 \mathrm{rpm}$ for the BR44 MC and between 35 and $49 \mathrm{rpm}$ for the ProNectin-F MC. Thus, up to 2.1-fold higher impeller speeds were required to suspend theoretical growth surfaces of $180 \mathrm{~cm}^{2}$ and $360 \mathrm{~cm}^{2}$ for the BR44 MC. Comparable observations were also found for the $N_{s 1}$ criterion, which was between 90 and $102 \mathrm{rpm}$ for the BR44 MC and between 44 and $60 \mathrm{rpm}$ for the ProNectin-F MC (see Supplementary Material “Calculation of important biochemical engineering parameters"). The resulting Reynolds numbers for the determined impeller 
speeds indicated that an MC suspension was achieved in a Corning spinner flask under transient fluid flow conditions. This finding was in good agreement with observations from Kaiser et al. [38] and Leber et al. [43] for different kinds of MCs. Based on the values determined for $N_{s 1 u}$ and $N_{s 1}$, the specific power input $(P / V)$ and the local volumeweighted mean shear stress $\left(\tau_{n t}\right)$ values were derived according to the method outlined by Jossen et al. [39]. Taking the $P / V$ and $\tau_{n t}$ into account, up to 4.4 and 2.2-times higher values were required to suspend the $B R 44 \mathrm{MC}$ than for the ProNectin-F MC, which can be explained by the different chemical nature of the two polymers.
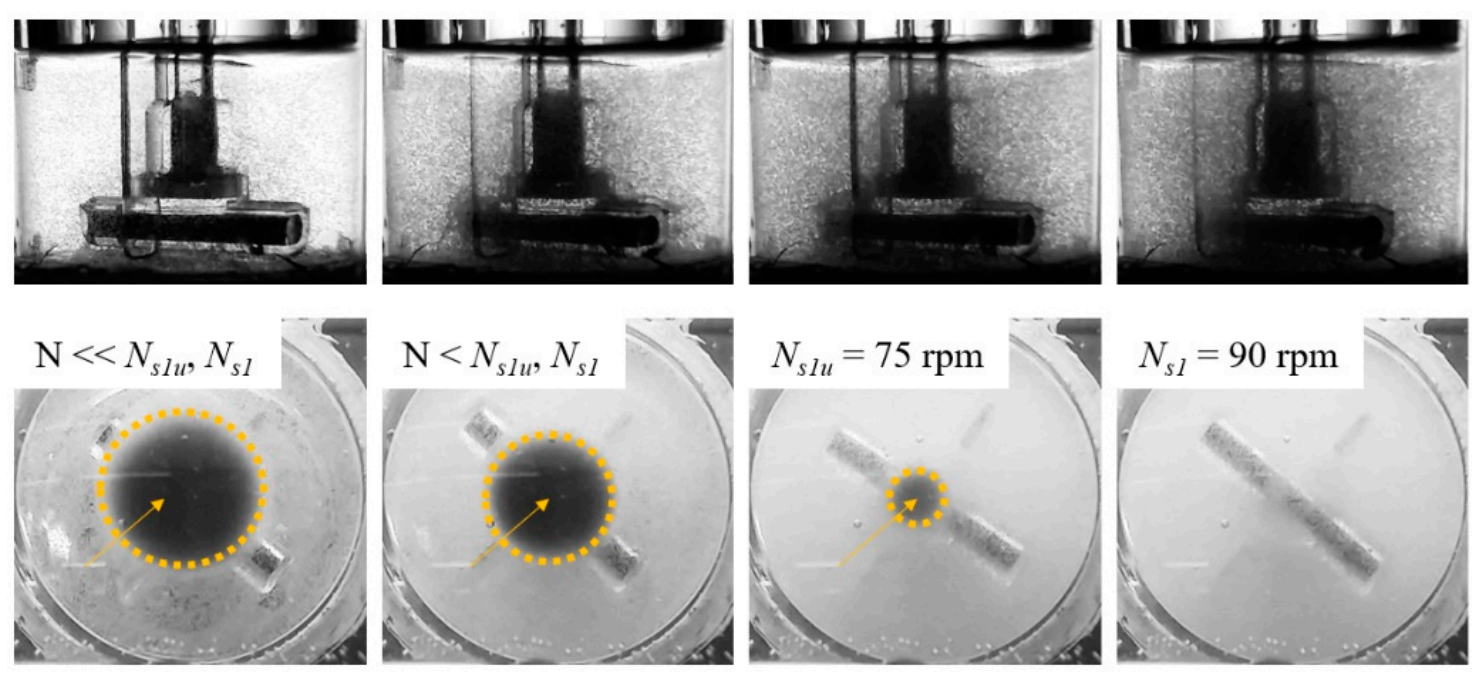

Figure 5. BR44 MC suspension dynamics. Photographic pictures (side and bottom view) of the MC distribution during the suspension studies. $N_{s 1}$ was defined as the impeller speed required just entirely to suspend all MCs. $N_{s 1 u}$ was defined as the lower limit of $N_{s 1}$, meaning that some MCs were still located at the bottom of the flask, but none were at rest.

Table 2. Overview of $N_{s 1 u} / N_{s 1}$ and dependent biochemical engineering parameters. $\left.{ }^{*}\right) P / V$ values and (**) local volumeweighted mean shear stress levels were derived from Jossen et al. [39]. $\mathbf{u}_{\text {tip }}$ indicates the maximum expected fluid velocities in a stirred bioreactor. Re is used to classify the fluid flow regime in a stirred bioreactor. $P / V$ represents an important parameter in terms of process scale-up and the estimation of hydrodynamic stresses. $\tau_{\text {nt }}$ gives an overview of the hydrodynamic stress acting on the cells in a stirred bioreactor system.

\begin{tabular}{|c|c|c|c|c|c|c|}
\hline & Theoretical $\mathrm{A}_{\mathrm{MC}}\left(\mathrm{cm}^{2}\right)$ & $N_{s 1 u} / N_{s 1}(\mathrm{rpm})$ & $u_{t i p}(\mathrm{~m} / \mathrm{s})$ & $\operatorname{Re}(-)$ & $P / V^{*}\left(\mathrm{~W} / \mathrm{m}^{3}\right)$ & $\tau_{\mathrm{nt}}{ }^{* *}\left(10^{-3} \mathrm{~Pa}\right)$ \\
\hline \multirow{2}{*}{ BR44 } & 180 & $75 / 90$ & $0.16 / 0.19$ & $2095 / 2514$ & $1.42 / 2.31$ & $8.3 / 10.0$ \\
\hline & 360 & $85 / 102$ & $0.18 / 0.22$ & $2374 / 2849$ & $1.96 / 3.39$ & $9.4 / 11.3$ \\
\hline \multirow{2}{*}{ ProNectin-F } & 180 & $35 / 44$ & $0.08 / 0.09$ & $978 / 1229$ & $0.35 / 0.52$ & $3.8 / 4.8$ \\
\hline & 360 & $49 / 60$ & $0.11 / 0.13$ & $1369 / 1676$ & $0.62 / 0.88$ & $5.4 / 6.6$ \\
\hline
\end{tabular}

\subsubsection{BR44 Stability under Stirred Conditions}

Figure 6A1,A2 shows light microscopic pictures of the $B R 44 \mathrm{MC}$ during the stability tests in the Corning spinner flasks. During the 14-day incubation period at $N_{s 1 u}(85 \mathrm{rpm})$, no significant increase in debris or broken BR44 MCs was observed, indicating that the BR44 MC was stable under culture-relevant conditions. However, the size distribution analysis after 14-days showed a decrease in the MC size distribution (Figure 6B) MCs' mean diameter decreased by up to $37 \%$, suggesting the MCs shriveled during the 14-day incubation period under stirred conditions. However, the MCs' shrinkage can be explained by the biodegradable property of PLGA and was, therefore, to be expected (see also Figure S6). 

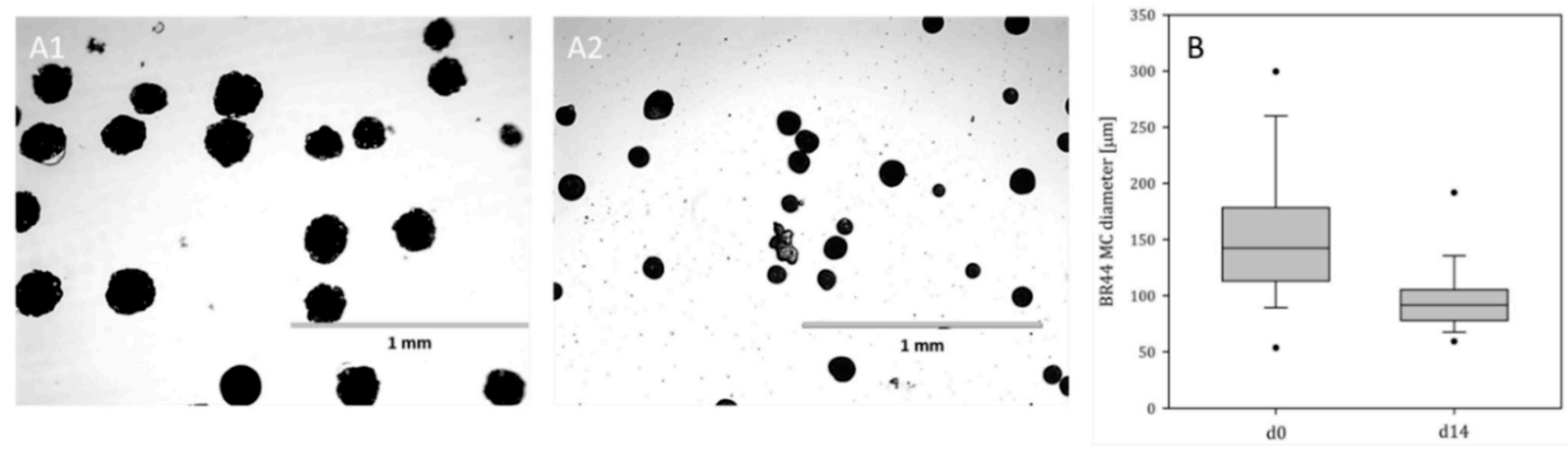

Figure 6. BR44 stability and size distribution. (A1,A2) Phase-contrast light microscopic pictures of the BR44 MC during the stability test in the Corning spinner flask $\left(N=N_{s 1 u}\right)$ at day zero and 14 . (B) Size distribution after equilibration $(4 \mathrm{~h})$ of the BR44 MC in UrSuppe (day 0) and after 14 days incubation under stirred conditions.

\subsection{Cultivation Studies}

\subsubsection{Attachment and Growth of the ASC52telo on BR44 MCs under Static Conditions}

In static culture tests, the $B R 44$ prototype obtained good results without using particular protocols. Therefore, we performed a titration to defined the optimal cell density to use with the BR44 MCs. Examples of cell attachment and growth on the BR44 MCs are shown in Figures 7 and 8 and Supplementary Material Figure S7 The BR44 MCs were entirely colonized by the ASC52telo cells, and the formation of large aggregates was observed after a few days of culture in static conditions with the UrSuppe medium. Therefore, the $B R 44 \mathrm{MC}$ is a three-dimensional (3D) scaffold suitable for growing human cells in xenoand serum-free conditions. Since it is often challenging to quantitatively detach cells from the MCs on which they have grown, a protocol based on nuclei counts was developed. A cell lysis buffer solution extracts the nuclei that can subsequently be enumerated by flow cytometry, allowing their cell cycle status to be assessed. Therefore, it is possible to calculate the percentages of actively proliferated cells attached to BR44 (see Table 3, and for more details, see Supplementary Material Figures S8 and S9). ASC52telo cells proliferated well on BR44, with a 5/6-fold increase in cell numbers and an excellent active proliferation rate (over $50 \%$ on the last day of measurement) being measured over eight days of cultivation. Growth curve reported in Supplementary Material Figure S10. It was concluded that ASC52telo cells readily adhere to the BR44 MC prototype's surface and that a significant percentage of them continued to proliferate during the sampling days actively.

Table 3. Analysis of the nuclei by flow cytometry. The nuclei can be divided into three groups based on different DNA amount. The three phases of interest, G1, G2, and S, are distinguishable (see Supplementary Material Figures S8 and S9). The data are shown for the four measurements (day $1,3,6$, and 8 ). The table shows the number and percentages of nuclei found in G1, G2, or S phase for ASC52telo grown on BR44. The active proliferation percentage (APP) was calculated as follows: $\mathrm{APP}=((\mathrm{G} 2+\mathrm{S}) / \mathrm{G} 1) \times 100$.

\begin{tabular}{lccccc}
\hline & Nuclei & \% G1 & \% S & \% G2 & APP \\
\hline Day 1 & $40^{\prime} 760$ & 71.89 & 7.96 & 10.65 & 25.89 \\
Day 2 & $55^{\prime} 520$ & 56.54 & 17.99 & 15.47 & 59.18 \\
Day 6 & $230^{\prime} 960$ & 67.32 & 12.54 & 11.82 & 36.19 \\
Day 8 & $222^{\prime} 948$ & 55.97 & 14.15 & 15.48 & 59.94 \\
\hline
\end{tabular}



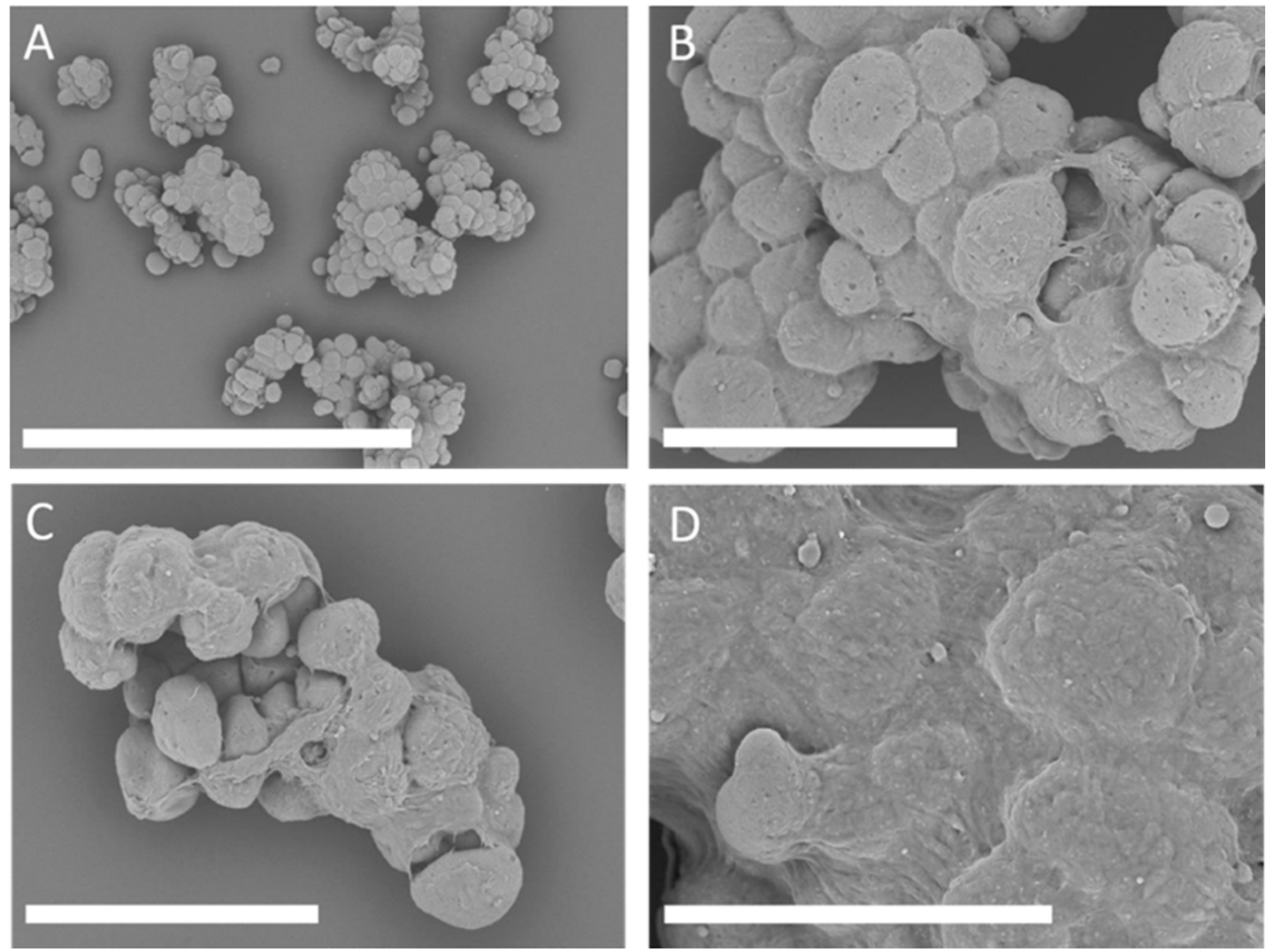

Figure 7. SEM microphotographs to confirm the presence of ASC52Telo cells on MC BR44 surface after four days of culture in static conditions. Fold magnification: (A): $50 \times$, scale bar 2 mm (B,C): $250 \times$, scale bar $300 \mu \mathrm{m}$ (D): $500 \times$, scale bar $200 \mu \mathrm{m}$. Interestingly, the cells are tiny and packed together, which is a feature often found with undifferentiated/immature cells.
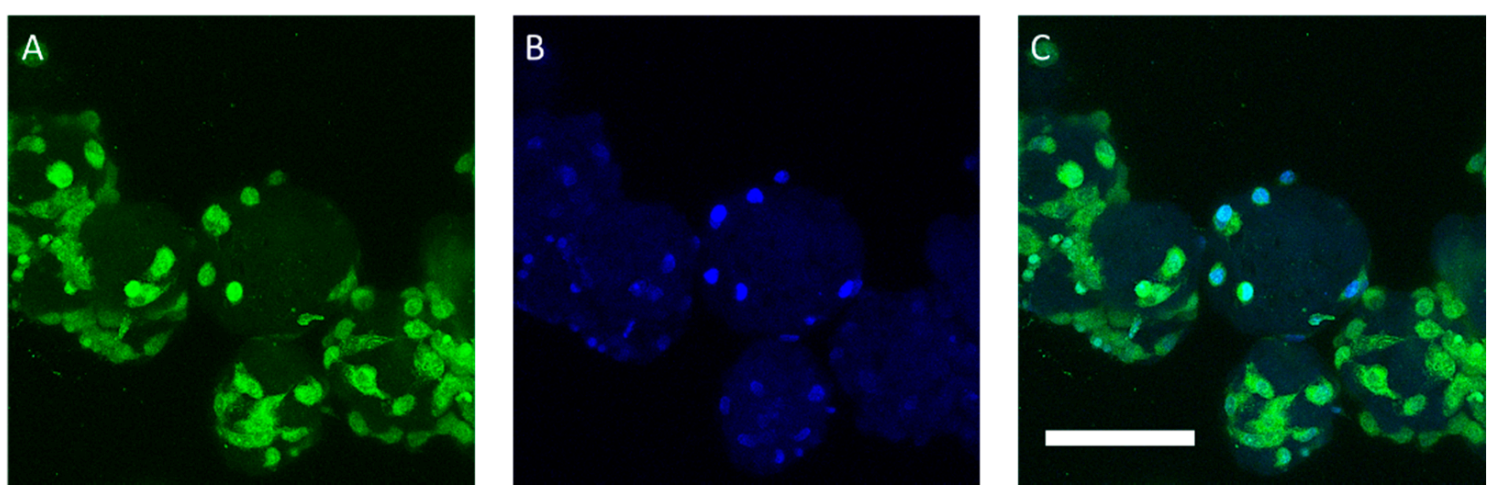

Figure 8. Confocal laser-scanning microscopy analysis of BR44 MCs after two days of culture. (A) The strong natural autofluorescence of the cells can be exploited to visualize the hASCs grown on the surface of the BR44 carrier. (B) The DAPI staining reveals the presence of several nuclei on the surface of BR44. (C) Merged. Magnification 400×, scale bar $100 \mu \mathrm{m}$.

\subsubsection{Proof-of-Concept: Spinner Cultivation with BR44 and ProNectin-F MCs}

Table 4 summarizes the results of the proof-of-concept cultivation. The data shows that the ASC52telo cells proliferated on the BR44 MC under dynamic conditions (growth curves can be found in Supplementary Material Figure S11). A maximum specific growth rate of up to $0.35 \mathrm{~d}^{-1}$ was obtained, which corresponded to a doubling time of $2.0 \mathrm{~d}$. Thus, a maximum cell density of $1.2 \times 10^{5}$ cells $/ \mathrm{mL}$ (EF 7.0) was achieved at the end of the cultivation. Cell growth on the ProNectin-F MC was 1.6-times faster $\left(\mu_{\max }=0.56 \mathrm{~d}^{-1}\right.$ and $\left.t_{d}=1.24 \mathrm{~d}\right)$. Thus, the maximum cell density $\left(7.5 \times 10^{5}\right.$ cells $\left./ \mathrm{mL}\right)$ and the expansion factor (21.3) were 7.5 and 3.1-times higher, respectively, after nine days of cultivation. This might result from the lower cell attach- 
ment efficiency of the BR44 MC compared to the ProNectin-F MC. In both cases, the ASC52telo cells consumed glucose $\left(q_{G l c, B R 44}: 21.7 \mathrm{pmol} / \mathrm{cell} / \mathrm{d}, q_{G l c, P N F}: 7.78 \mathrm{pmol} / \mathrm{cell} / \mathrm{d}\right)$ and produced lactate $\left(q_{\text {Lac,BR44 }}: 137.8 \mathrm{pmol} / \mathrm{cell} / \mathrm{d}, q_{\mathrm{Lac}, P N F}: 41.2 \mathrm{pmol} / \mathrm{cell} / \mathrm{d}\right)$ and ammonia $\left(q_{A m n, B R 44}:\right.$ $\left.7.3 \mathrm{pmol} / \mathrm{cell} / \mathrm{d}, q_{A m n, P N F}: 1.6 \mathrm{pmol} / \mathrm{cell} / \mathrm{d}\right)$. In both cultivations, no critical substrate or metabolite concentrations were achieved $\left(L a c_{P N F}=26.87 \mathrm{mmol} / \mathrm{L} ; L_{a c} c_{B R 44}=21.31 \mathrm{mmol} / \mathrm{L}\right.$, $\left.A m n_{P F N}=0.96 \mathrm{mmol} / \mathrm{L}, A m n_{B R 44}=0.65 \mathrm{mmol} / \mathrm{L}\right)$; however, cells growing on $B R 44 \mathrm{MC}$ could experience a high localized concentration of lactate, which would constantly be released from the MC core. This is suggested by the calculated amount of lactate (in pmol) released per cell and per day, which is three times higher for the BR44 MC ( 138 pmol/cell/day) than for ProNectin-F MC ( $\sim 41 \mathrm{pmol} / \mathrm{cell} /$ day). This high concentration of localized lactate may have been the reason for the slower growth rate and doubling time observed for the tests performed with BR44 MC, as lactate is known to inhibit cell growth [44]. Furthermore, we noticed that cultures based on the BR44 MC easily generate clusters, even under dynamic conditions. This phenomenon is much less relevant when ProNectin-F MC was used. Cell-MC clusters could lead to a decrease in cell density due to nutrient diffusion limitations to aggregate centers. The calculated average $Y_{\text {lactate/glucose }}$ values are superior to the theoretical values of 2 for both MCs type $\left(Y_{\text {Lac } / G l c, B R 44}=6.35 ; Y_{L a c / G l c, P N F}=5.29\right)$. This suggests that alternative substrates such as glutamine, serine, and possibly other amino acids are used for energy generation and contribute to the measured lactate concentration [45]. During these catabolic reactions, ammonia is produced, which we detected in significant quantities, especially in the presence of MC BR44 ( 4.5 times higher than with MC ProNectin-F), supporting the previous suggestion. It is well known that glutamine is chemically labile in the cell culture medium, and thus ammonia could arise through spontaneous hydrolyzation of this amino acid [46,47]. However, the amounts detected could not be explained with only the spontaneous degradation of glutamine in cell culture conditions. As low levels of ammonia in the cell culture medium are known to inhibit cell growth [31], the cells grown on MC BR44 would be at a further disadvantage compared to those grown on ProNectin-F, where ammonia concentration per cell and per day was approximately 4.5 times lower. Taken together, the findings suggest that the type of MC used has an influence on the type of metabolism adopted by the cells during cultivation.

Table 4. Overview of main growth-dependent parameters.

\begin{tabular}{|c|c|c|c|}
\hline \multicolumn{2}{|c|}{ Parameter } & \multirow{2}{*}{$\begin{array}{c}\text { BR44 } \\
0.35\end{array}$} & \multirow{2}{*}{$\frac{\text { ProNectin-F }}{0.56}$} \\
\hline$\mu$ & $\left(d^{-1}\right)$ & & \\
\hline$t_{d}$ & (d) & 2.01 & 1.24 \\
\hline Att $_{\text {eff }}$ & $(\%)$ & 38.7 & 78.2 \\
\hline$X_{\max }$ & $\left(10^{5}\right.$ cells $\left./ \mathrm{mL}\right)$ & 1.2 & 7.5 \\
\hline$E F$ & $(-)$ & 7.0 & 21.3 \\
\hline$Y_{L a c / G l c}$ & $(\mathrm{mmol} / \mathrm{mmol})$ & 6.35 & 5.29 \\
\hline qGlc & $(\mathrm{pmol} / \mathrm{cell} / \mathrm{d})$ & $21.74 \pm 9.12$ & $7.78 \pm 1.83$ \\
\hline$q L a c$ & $(\mathrm{pmol} / \mathrm{cell} / \mathrm{d})$ & $137.88 \pm 40.64$ & $41.24 \pm 19.39$ \\
\hline$q A m n$ & $(\mathrm{pmol} / \mathrm{cell} / \mathrm{d})$ & $7.32 \pm 3.71$ & $1.61 \pm 0.74$ \\
\hline
\end{tabular}

$\mu$ : Specific cell growth rate. $t_{d}$ : Doubling time of cell population. Att $t_{\text {eff: }}$ Attachment efficiency. $X_{\max }$ : Maximum cell concentration on planar growth surface. EF: Expansion factor. $Y_{\text {Lac/Glc }}$ : Lactate yield per glucose equivalent. $q$ Glc: Specific glucose consumption rate. $q$ Lac: Specific lactate production rate (growth-dependent). qAmn: Specific ammonium production rate (growth-dependent).

\subsection{Cell Analytics}

3.4.1. Flow Cytometry Analysis of ASC52telo Cells Cultured in Static 2D or Dynamic 3D Conditions

It was desirable to verify whether the ASC52telo cells growing on BR44 (3D conditions) express the same standard surface markers and maintain the same stemness level as a batch of the same cells cultivated in traditional cell culture vessels (2D conditions). Flow cytometry analysis of some common surface antigens suggested no significant differences between cells grown in 2D and those grown in 3D on BR44. Essential markers for stemness are preserved (CD73, CD90, and CD105), and adipogenic markers (CD34, CD36, and CD146) upregulated during adipogenic differentiation are not expressed in 3D conditions 
(see Figure 9 and Supplementary Material Figures S12 and S13) [48]. CD61 is a control marker that is usually not expressed by human fibroblasts [49].

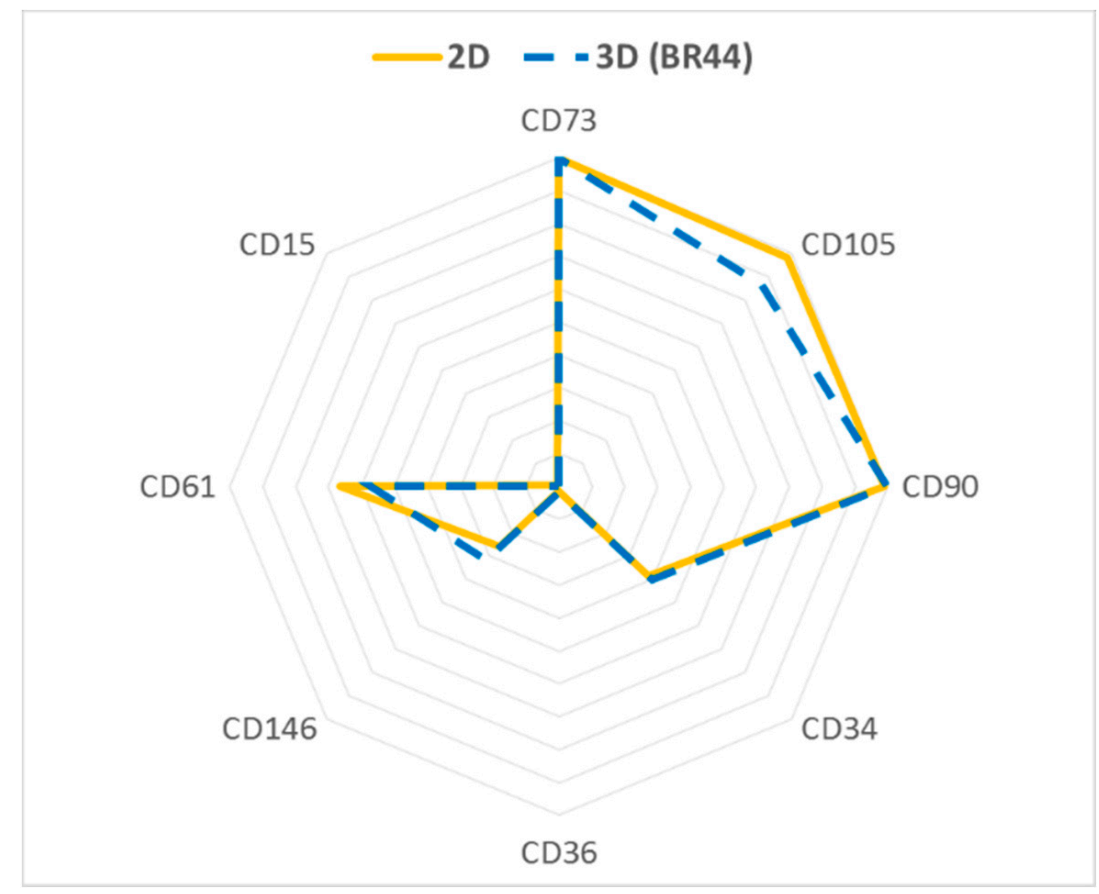

Figure 9. Flow cytometry data were summarized and depicted using a "Radar Plot" for ASC52telo cells cultured in xeno- and serum-free conditions (UrSuppe). The diagram shows the percentage of positive cells for the respectively indicated surface marker. Cells were cultured either in 2D (T25 flask) or on the BR44 (3D condition).

3.4.2. Expression Levels of Some Essential Genes Involved in Cell Stemness or Cell Differentiation Measured by RT-qPCR

Several genes have been discovered to seal the undifferentiated status of hASCs and other genes required for their differentiation (Figure 10A). Further information about a selection of these genes, including a short description and references, can be found in Supplementary Material Tables S6 and S7. Some of them are useful as markers in RT-qPCR assays to check the in vitro expanded cells' differentiation status. In these experiments, ASC52telo cells were grown in standard cell culture vessels (2D static) or spinner flasks on BR44 (3D dynamic). RT-qPCR measured the expression levels of some of the selected marker genes, and the values were compared to those obtained in static $2 \mathrm{D}$ conditions. PREF1, WISP2, ZFP521, and SOX9 are among the essential genes linked with the undifferentiated status and against differentiation of adipose tissue progenitor cells. Interestingly, an increase in the expression of these markers was observed in 3D cultures. PPARG, ZFP423, DKK1, and RUNX2, are related to the commitment to an adipogenic (chondrogenic for RUNX2) lineage and differentiation. In 3D cultivations, a down-regulation of two of these important genes (PPARG and DKK1) was observed (see Figure 10B), meaning better preservation of the undifferentiated status of the cells compared to the 2D static situation. 
A

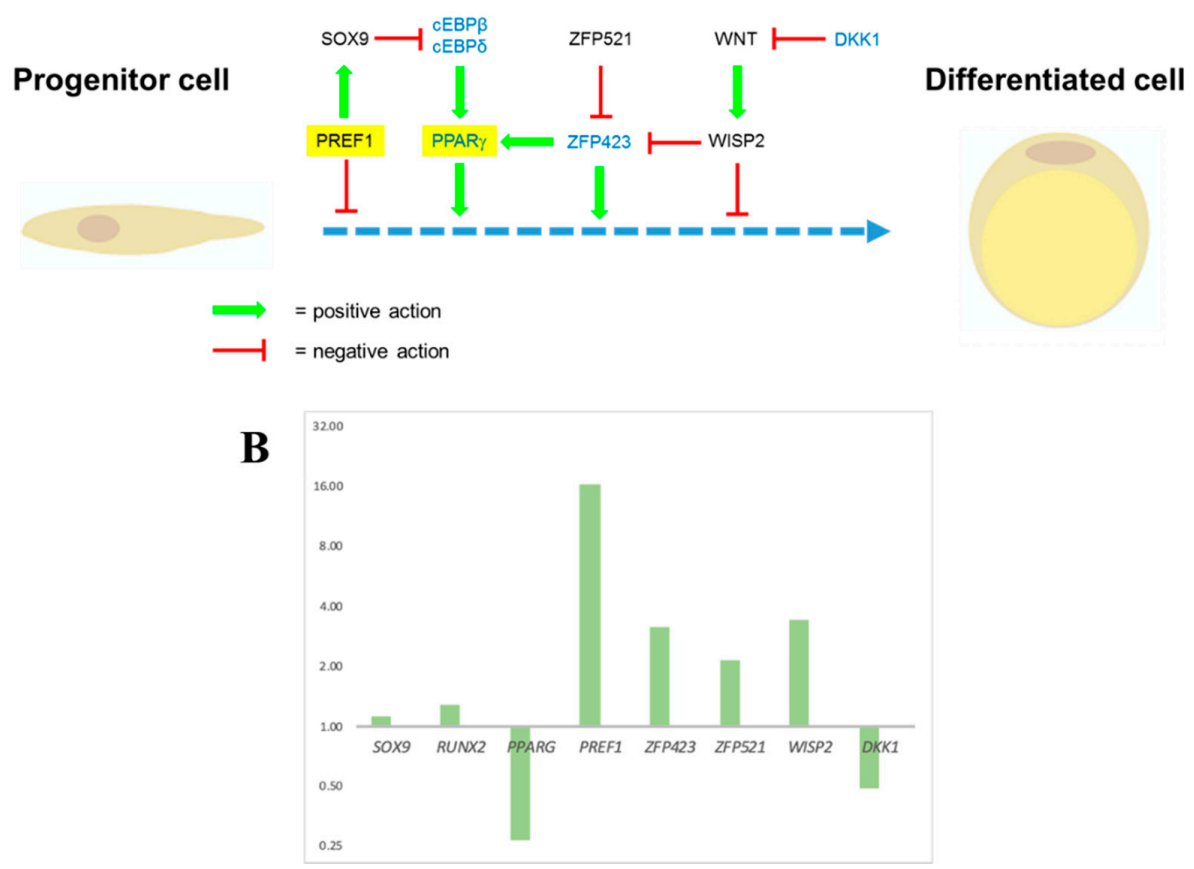

Figure 10. Expression ratio measured by RT-qPCR of some essential genes which regulate positively or negatively the adipocyte differentiation process. (A) The illustration schematically shows the relationship between different factors that positively or negatively controls adipogenesis. Two of them are particularly important: PPREF1 is known to inhibit adipogenesis and, PPARG, considered the master regulator of adipose tissue development and differentiation. The blue dotted line represents the various differentiation stages that lead to a mature adipocyte starting from a progenitor cell. Further information and references about the marker genes used can be found in Supplementary Material, Tables S6 and S7. (B). Representative experiment showing differences in marker genes expression between ASC52telo cells grown in static 2D or defined dynamic 3D conditions. The normalized expression ratio of the different markers for the defined dynamic 3D tests is related to the static $2 \mathrm{D}$ condition values.

3.4.3. Comparing the Secretome Profile of ASC52telo Cells Grown in Standard Static 2D vs. Dynamic 3D Conditions

Since some polypeptides are only produced and secreted during certain precise stages of development or maturation, they can be used to diagnose a specific metabolic state or a specific differentiation degree of the cells under investigation. To assess the presence of 58 human adipokines, we used a commercially available "Proteome Profiler Human Adipokine Array" (see Table 5, Figure 11, and Supplementary Material Figure S14 and Table S8). Interpreting and finding a biological sense for a proteome profiler array is always very difficult, especially if many polypeptides are detected. In this case, which fortunately is not too complex, we notice some trends that allow us to interpret the obtained results. First, the detected polypeptides were already associated by other reports with the adipose tissue secretome (for a review, see [50]). Second, to facilitate the data's comprehension, it is possible to group the secreted polypeptides according to some characteristic traits that unite them. Two signature adipokines (adiponectin and leptin) for differentiated cells were undetectable in the test membranes, and the spot corresponding to Nidogen/Entactin was very weak. These results prove that most ASC52telo cells remain undifferentiated and immature. We detected three Cathepsin family members. These proteins are proteases that play different crucial roles in mammalian cellular turnover. Cathepsin $\mathrm{S}$ promoted human preadipocyte differentiation [51] and was found only in the culture medium of cells grown under 2D conditions. A critical role of the Insulin-like growth factor-binding proteins (IGFBPs) is to regulate Insulin-like growth factors (IGF-I and IGF-II) action by controlling the accessibility of these peptide hormones to their receptors [52]. Both IGF-I [53] and IGF- 
II $[54,55]$ are pro-adipogenic. It has been shown that IGFBP-4 binds IGF-I and its expression negatively correlates with adipose tissue growth [56]. IGFBP-6 is not well characterized but is likely to be anti-adipogenic, too, as it can bind IGF-II [57]. Pregnancy-associated plasma protein-A (PAPP-A) is a zinc metalloproteinase regulating local insulin-like growth factor (IGF) action through cleavage of inhibitory IGFBPs, in particular IGFBP-4. This is the primary mechanism by which PAPP-A enhances local IGF bioavailability for receptor activation. PAPP-A is expressed primarily by pre-adipocytes in fat tissue [58]. So, IGFBP-4, IGFBP-6, and PAPP-A belong to a circuit that regulates IGFs' availability, which in turn positively regulates adipogenesis. IGFBP-4 and IGFBP-6 were detected in the supernatants of cells cultured in 2D and 3D/PNF MC conditions, but not when the BR44 MC was used, whereas PAPP-A only in 2D condition. The proteome profiler array also highlighted the presence of some cytokines [59] and chemokines [60] in the cell-conditioned culture media: IL-6, CXCL/IL-8, CCL2/MCP-1, MIF, and CCL5/RANTES. Interestingly, IL-6, CCL2/MCP-1, and CCL5/RANTES were detected only in cells grown in 2D conditions. On the other hand, IL-8 and MIF were detected in 2D and 3D (see Table 5 and Figure 11). Pentraxin 3 (PTX3), also known as tumor necrosis factor (TNF)-inducible gene 14 protein (TSG-14), is a pattern recognition molecule that functions in innate immunity and is a useful biomarker of a pro-inflammatory status [61]. Remarkably, this polypeptide was detected only in the supernatants of cells cultured in 2D and 3D/PNF MC conditions, but not when the BR44 MC was used. These observations suggest that the defined dynamic $3 \mathrm{D}$ conditions might lead the cells to secrete fewer inflammatory factors, and BR44 MC seems more suitable than PNF MC to induce this phenomenon. As a last interesting factor found only in the supernatant of cells grown in 2D or 3D combined with BR44 MC, there is Serpin E1/PAI-1. Plasminogen activator inhibitor-1 (PAI-1), a serine protease inhibitor family member, inhibits fibrinolysis and has complex cellular matrix interactions. PAI-1 deficiency or inhibition stimulates adipocyte differentiation. Therefore it can be considered an anti-adipogenic factor [62]. In summary, these results suggest that the secretion profile of ASC52telo depends on the cultivation system (standard static 2D vs. dynamic 3D). Interestingly, when these cells grew on BR44 in a dynamic system, the secretion profile is less complex. This may suggest that the cells remain more immature, thus preserving better "stemness". This observation is in good agreement with the results obtained by RT-qPCR. Ultimately, culturing ASC52telo cells on MCs in a dynamic 3D cell culture system using the UrSuppe medium seems to enhance the cells' undifferentiated status and reduces the secretion of pro-inflammatory mediators.

Table 5. Summary of the relevant secreted factors of ASC52telo cells cultured in standard cell culture vessels (2D) or dynamic conditions (spinner flask, 3D). In this latter case, the cells were cultured either on BR44 MC or commercial ProNectin-F (PNF) MC. Interestingly, the secretion profile of cells grown in 3D is less complex than the one obtained in the 2D condition. Moreover, when the BR44 MC is used, the number of secreted polypeptides detected is further reduced compared to PNF MC. These results suggest that the secretome of ASC52telo cells can be influenced by the cell culture conditions (2D vs. 3D) and the microcarrier type on which they grow (BR44 vs. PNF). A less complex profile of secreted adipokines in 3D conditions may also signify that the ASC52telo better preserve their undifferentiated status when they grow on MCs in a defined dynamic system. The UrSuppe medium was used in all conditions tested for these investigations. For more details about these experiments, see Supplementary Material Figure S14.

\begin{tabular}{cccc}
\hline Analyte/Control & $\begin{array}{c}\text { 2D } \\
\text { ASCs 52telo }\end{array}$ & $\begin{array}{c}\text { 3D } \\
\text { ASCs 52telo BR44 }\end{array}$ & $\begin{array}{c}\text { 3D } \\
\text { ASCs 52telo ProNectin-F }\end{array}$ \\
\hline Cathepsin D & $\mathrm{X}$ & $\mathrm{X}$ & $\mathrm{X}$ \\
Cathepsin L & $\mathrm{X}$ & $\mathrm{X}$ & \\
Cathepsin S & $\mathrm{X}$ & & $\mathrm{X}$ \\
IGFBP-4 & $\mathrm{X}$ & $\mathrm{X}$ \\
IGFBP-6 & $\mathrm{X}$ & & \\
\hline Pappalysin-1/PAPP-A & $\mathrm{X}$ & & \\
\hline
\end{tabular}


Table 5. Cont.

\begin{tabular}{|c|c|c|c|}
\hline Analyte/Control & $\begin{array}{c}\text { 2D } \\
\text { ASCs 52telo }\end{array}$ & $\begin{array}{c}\text { 3D } \\
\text { ASCs 52telo BR44 }\end{array}$ & $\begin{array}{c}\text { 3D } \\
\text { ASCs 52telo ProNectin-F }\end{array}$ \\
\hline IL-6 & $X$ & & \\
\hline CXCL8/IL-8 & $X$ & $X$ & $X$ \\
\hline CCL2/MCP-1 & $X$ & & $x$ \\
\hline MIF & $x$ & $x$ & $x$ \\
\hline CCL5/RANTES & $x$ & & \\
\hline Pentraxin-3/TSG-14 & $X$ & & $X$ \\
\hline Serpin E1/PAI-1 & $X$ & $x$ & \\
\hline TIMP-1 & $X$ & $x$ & $X$ \\
\hline Endocan & $x$ & & \\
\hline HGF & $x$ & & $x$ \\
\hline ICAM-I/CD54 & $x$ & & \\
\hline Nidogen-1/Entactin & $x$ & & $x$ \\
\hline
\end{tabular}

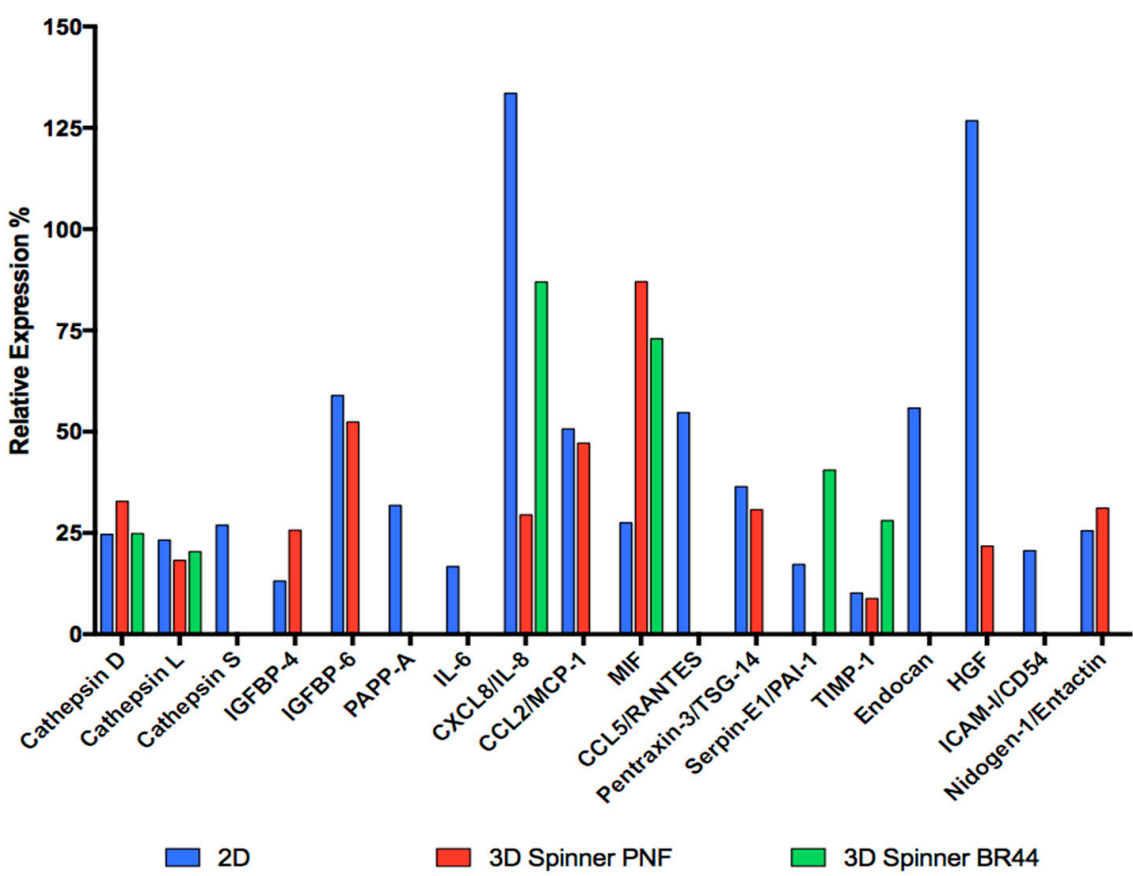

Figure 11. Comparison of the secretome profiles of ASC52telo cells cultured in standard cell culture vessels (2D) or dynamic conditions (spinner flask, 3D). In this latter case, the cells were cultured either on BR44 MC or commercial ProNectin-F MC. The calculated levels are expressed as a percentage relative to the reference spot present on the membrane. Remarkably, the secretion profile depends on the three culture conditions (2D, 3D spinner ProNectin-F, and 3D spinner BR44) tested in this study.

\section{Discussion}

PLGA is the most widely used synthetic biodegradable material due to its excellent biocompatibility, non-toxicity, and non-immunogenicity [63]. Indeed, PLGA is generally recognized as safe for use in particular pharmaceutical products such as degradable sutures, stents, screws, bone plates, and wound dressing by international regulatory agencies, such as the United States Food and Drug Administration (FDA) and the European Medicines Agency (EMA). PLGA is considered the "material of choice" to manufacture biodegradable MCs or scaffolds since its degradation products are quickly metabolized in the body via the Krebs cycle [44,45]. PLGA has also been used as a core polymer to manufacture MCs to culture anchorage-dependent cells, which require large surface areas for attachment and growth. However, pure PLGA carriers do not inherently possess cell-adhesion 
motifs. Different approaches have been proposed to functionalize the MC surface and allow efficient attachment and proliferation of anchorage-dependent cells [21]. Therefore, it was decided to synthesize gelatin-PLGA composite MCs by emulsifying gelatin in a PLGA/dichloromethane solution, followed by a modified water-in-oil-in-water double emulsion solvent evaporation method [25]. Gelatin is a naturally derived polymer, has a chemical structure similar to collagen, thus mimicking the natural extracellular environment [64]. However, it is a product of animal origin and, therefore, potentially able to initiate an immunological response or transmit zoonotic diseases is a drawback. Nevertheless, gelatin has a long history of clinical use, with few adverse outcomes [65,66]. Moreover, bovine gelatin was replaced by porcine gelatin to avoid Bovine Spongiform Encephalopathy (BSE) related issues. For the orthopedic application of stem cells, it is realistic to plan for ex-vivo cultivation, a manufacturing period of approximately two months. Three to four weeks are needed to amplify the stem cells and as many weeks again to differentiate them into chondrocytes or osteocytes. It is known that during differentiation, the extracellular matrix (ECM) is replaced with one more suited to their new role as mature cells [67]. We estimate that porcine gelatin makes up approximately $10 \%$ of the MC. Thus, it is very likely that there will be very little residual porcine gelatin remaining at the time of implantation of the engineered tissue, reducing the risk of an immunological reaction. Nevertheless, further steps are planned to replace porcine gelatin with recombinant human ECM proteins or biomimetic peptides [68]. This is also a necessary step toward respecting the ethical or religious convictions of a considerable number of human beings who do not allow the consumption or use of products of porcine or bovine origin.

Several types of MCs were manufactured and examined. Still, only a specific combination of organic and biological polymers, shape, and porosity, among other tested parameters, resulted in a MC prototype with the desired functionality and promoting cell attachment and proliferation. The BR44 MCs allow ASC52telo cells to attach to their surface, grow in a defined serum-free cell culture medium in a static or a dynamic system, and maintain or even enhance their undifferentiated status. The biochemical engineering parameters were also very close to those found for commercial non-biodegradable MCs (e.g., ProNectin-F). We also experimentally determined the biophysical characteristics of $B R 44 \mathrm{MC}$ and analyzed the morphology and distribution of gelatin on the microspheres. We found that $B R 44 \mathrm{MC}$ is very porous, and the gelatin is homogeneously blended with the synthetic polymer. The chemical structure of PLGA is illustrated in Figure 12A, and a cartoon in Figure 12B tries to reproduce, in a very schematic and naive way, how the biocompatible scaffold shaping BR44 MC might look like at the molecular level. PLGA forms a compact and dense nano-fibrous structure on which gelatin deposits and attaches non-covalently to the synthetic polymer.

A

PLGA: Poly(lactic-co-glycolic acid)

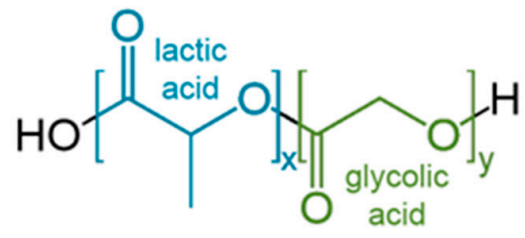

$x$ and $y$ indicate the number of times each unit repeats.
B

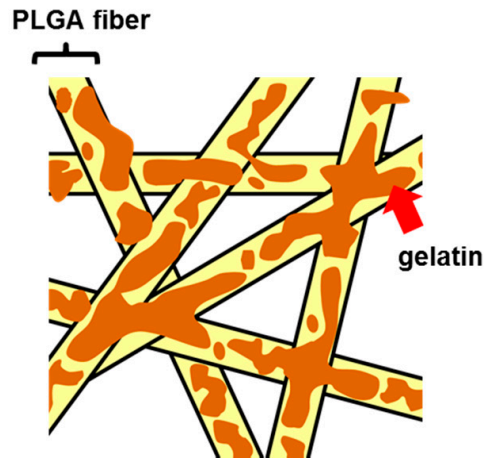

Figure 12. Chemical structure of PLGA (A) and cartoon (B) suggesting how the PLGA/gelatin mix might resemble. (A) Structure of PLGA. (B) Tight and dense nano-fibrous structure of embedded gelatin on PLGA fibers. The interaction between the two polymers is non-covalent. The uniform distribution of the gelatin allows the formation of a biodegradable MC with cell adhesion suitable surfaces. 
During these studies, we had the opportunity to understand the drawbacks of biodegradable PLGA based MCs. First, lactic acid is continuously released from this MC type during the cell culture procedure and adds to that secreted by cells. Indeed, as shown in Table 4, we measured about three times more lactic acid when the ASC52telo were grown on BR44 (qLac: $138 \mathrm{pmol} / \mathrm{cell} / \mathrm{d}$ ) compared to the value found when ProNectin-F MCs (coated polystyrene microsphere, qLac: 41 pmol/cell/d) were used for the experiments. Lactic acid can inhibit cell growth [44]: ASC52telo growing on BR44 could experience a much higher local lactic acid concentration than the cells cultured on ProNectin-F MCs. Therefore, this could explain the lower growth rate and the higher doubling time of a BR44 MC-based culture compared to one dependent on ProNectin-F MCs. The type of MC used to culture the ASC52telo cells influences their metabolism. Indeed, with BR44, there is also a higher ammonia production per cell and per day. It is known that a low level of ammonia in the cell culture medium inhibits cell growth. This, together with the lactic acid production, could explain the lower cell yield obtained with MC BR44. Second, the $B R 44 \mathrm{MC}$ is more challenging to handle than the synthetic ProNectin-F counterpart since it easily sticks to pipettes and other equipment commonly used in the laboratory to transport or measure a powder or a liquid. However, we noticed that this characteristic is also shared by other MCs manufactured with organic or biological polymers, such as Cultispere S and G, Cytodex 3, and Celnest' Macroporous MCs (Fujifilm). This problem can be alleviated by using "low retention" (Repel Polymer Technology, RPT) tips and pipettes. Third, this innate propensity, typical for MCs with a biopolymer core to stick together, is also maintained in culture with cells. Thus, even under dynamic conditions, this can lead to the formation of large aggregates. Therefore, it is necessary to optimize the stirring conditions to reduce this phenomenon, which may lead to a decrease in cell density due to the limitation in the diffusion of nutrients to the center of large cell-MC clusters. Therefore, MCs with a biopolymer core require a more laborious setup concerning the seeding densities and the agitation parameters compared to classic MCs with a synthetic core. Fourth, despite the sedimentation velocity of the $B R 44$ being excellent $(\approx 0.63 \mathrm{~mm} / \mathrm{s})$ and comparable to the commercial MC ProNectin-F ( $\approx 1.46 \mathrm{~mm} / \mathrm{s})$, the impeller speed necessary to keep the BR44 in suspension was up to 2.1-fold higher than the one used for the MC ProNectin-F. Jossen et al. [39,69] have recently shown that cells start to experience increased hydrodynamic stress above a specific impeller speed, which leads to a significant decrease in the specific growth rate. Thus, together with the higher concentration of lactate and ammonia, this observation can explain the decreased cell yield when the BR44 is used to culture ASC52telo cells. A possible explanation for this observation is that BR44 is very porous and has an irregular shape. This could increase the hydrodynamic drag and require a higher impeller speed to keep the carriers in suspension. Finally, while synthetic MCs, such as ProNectin-F, have perfectly spherical, smooth, and are all approximately the same size, those made with organic or biological polymers often have an irregular shape, inhomogeneous dimensions, and can be very porous (see Figures S2 and S3). This makes it difficult to determine with certainty the total surface available for growing cells. Consequently, finding the optimal seeding density in these cases is more based on empirical tests than on precise calculations.

Growth kinetics of ASC52telo on BR44 is similar to other MCs culture, consisting of slow initial growth, followed by an exponential growth phase until cells reach a stationary level after, determined by the surface/nutrient availability, after a week [70]. In our previous paper, we study primary human ASCs growth parameters in UrSuppe on commercial MC. We observed that the number of cells fluctuated around a specific maximum value determined by the system [37]. One of the most important preliminary results obtained after these experiments is that the undifferentiated state of the ASC52telo cells is very well preserved when growing on biodegradable MC. This is independent of the cell culture system since this was observed both in static and dynamic (stirred flask) conditions. In static or dynamic conditions, we found that cells grown in 3D on BR44 showed a better "gene expression profile for stemness" than the same cells cultured on traditional 2D surfaces 
(as shown in Figure 10B). We also observed that the secretion profile of ASC52telo cells depends on the cultivation system (standard static 2D vs. dynamic $3 \mathrm{D}$ ) and the MC type on which the cells grow (BR44 vs. ProNectin-F, see Table 5, Figure 11, and Figure S14). These observation are in accordance to previous papers that indicates that $3 \mathrm{D}$ environment mimic the in vivo conditions and are able to better preserve stemmnes [71]. Interestingly, when these cells expand on MCs in a dynamic system, the adipokines profile is less complex. This could mean that the cells remain more immature, thus better preserving their stemness. This observation agrees with the results obtained by RT-qPCR. We also noted that the type of MC used to grow the cells also influences the type of metabolism adopted during the culture period. So, we concluded that although the system based on an agitated bioreactor, microcarrier, and a defined serum-free medium may seem very artificial, the cells like it and maintain the same or a superior undifferentiated status compared to cells grown in standard 2D conditions. We thought of explaining this phenomenon with the following hypothesis. Except for blood and endothelial cells, all the other cells are normally never in contact with serum. They are in contact with the interstitial fluid, which has a lower concentration of proteins than serum and is specific for each tissue or organ due to a unique composition of secreted polypeptides and metabolic molecules [12,13]. Paradoxically, it is similar in composition to a serum-free medium, which is generally not as complex as serum and is specific to the cell type of interest. Furthermore, cells are organized in 3D structures, and they experience movements and hydrodynamic and shear stresses: Fluids flow through, contractions, movements, and motor activity are widespread actions in the animal kingdom. Thus, it may be possible that the conditions created in an agitated bioreactor somehow recreate the natural situation experienced by the cells in the body better than in a standard 2D cell culture vessel.

In conclusion, BR44 is a suitable MC for the cultivation of ASC52telo in a defined xeno- and serum-free medium. Regenerative applications require high biomass that should be obtained using a defined system. Now that we have suitable biodegradable MCs and a chemically defined medium for human ASCs, we are ready to check whether we can reproduce these results with primary human cells. Furthermore, the UrSuppe medium could help study ex vivo the biology in healthy and dysfunctional states of adipocytes and their precursors in defined and controlled cell culture conditions.

Supplementary Materials: The following are available online at https:/ / www.mdpi.com/2076-3 417/11/3/925/s1, Figure S1: A pluriStrainer Mini $40 \mu \mathrm{m}$ is used to separates micro carriers (MCs) from the nuclei; Figure S2: scanning electron microscopy (SEM) microphotographs to show the morphology of some commercial dry MCs; Figure S3: SEM images to show the morphology of ProNectin-F MCs; Figure S4: SEM microphotographs to show the morphology of the MC were used as a negative control; Figure S5: Fluorescent microphotographs of the MCs after reaction with the CF633 dye; Figure S6: SEM microphotographs of the carrier BR44 after four days in culture without cells; Figure S7: DAPI stained samples of ASCs52Telo cultured on the prototype MC BR44 and the commercial MC ProNectin-F in static condition for two days; Figure S8: Analysis of nuclei released from the microcarrier-based culture of ASC52telo cells using 7-AAD and volumetric flow cytometry; Figure S9: L-Mimosine stops proliferating ASC52telo cells before the onset of DNA replication; Figure S10: Growth curve; Figure S11: Time-dependent profiles of cell densities in the Corning spinner flasks; Figure S12: Single-parameter histograms for fourescence activated cell sorting (FACS) analysis of known surface markers on AC52Telo cells cultured in serum-free conditions (UrSuppe) on standard 2D cell culture vessels or microcarriers BR44 (3D); Figure S13: FACS analysis of known surface markers on AC52Telo cells cultured in serum-free conditions (UrSuppe): Comparison between cells grown on classical cell culture vessels (2D) or microcarriers ProNectin-F (PNF); Figure S14: Comparing the adipokines secretion profile of ASC52telo cells. Table S1: Published case studies for culture systems for human cells based on dissolvable or biodegradable microcarriers; Table S2: Materials; Table S3: Reverse transcription detailed procedure; Table S4: Primer sequences; Table S5: RT-qPCR cycle conditions; Table S6: Overview of measured stemness maintenance genes; Table S7: Overview of measured differentiation regulators/markers; Table S8: Human adipokine array. 
Author Contributions: T.T., M.M. and R.E. conceived and designed the experiments; Y.H. M.L. produced all the microcarriers used in this study; F.M., S.P. and T.T. performed the 2D static experiments and carried out the cell analytical measurements/analysis; V.J. performed the bioengineering characterization of the carriers and performed the dynamic experiments; F.M., S.P., M.L. and V.J. wrote the original draft of the paper; F.M., S.P., M.L., V.J., T.M., Y.H., M.M., R.E. and T.T. wrote, reviewed, and edited the original manuscript. All authors have read and agreed to the published version of the manuscript.

Funding: This research was funded by the Cardiocentro Ticino Foundation (CCTF), the Foundation for Cardiological Research and Education (FCRE), Micro-Sphere SA (6998 Monteggio, Switzerland), and by Swiss Federal Innovation Agency CTI (Commission for Technology and Innovation), project No. 25275.2 PFLS-LS.

Acknowledgments: We are grateful to Dante Moccetti (Director of Cardiocentro Ticino) for his interest and continuous support with the project. We also thank Ferruccio Messi (Cell Culture Technologies LLC, 6929 Gravesano, Switzerland) for preparing the customized basal cell culture media and for his help during the initial phases of the project. We thank the following students and former collaborators of the University of Applied Sciences in Zurich (ZHAW) who helped us at the very beginning of the project: Carolin Poch, Anita Ott, Camilla Margaroli, Laura Ramos Llanos, and Renate Lombriser. We are indebted to Maria Montilla (Grant Manager of Cardiocentro Ticino) for her excellent help in acquiring and managing funds for our research. We thank Darren Mace (ZHAW Wädenswill, English department) and Misha Teale (ZHAW Wädenswil, Institute of Chemistry and Biotechnology) for the excellent proofreading of the manuscript. We thank the anonymous reviewers for their constructive criticism that helped improve the manuscript.

Conflicts of Interest: Matias Lindner and Michele Müller are Sferalp SA employees who manufacture the microcarrier BR44. All the other authors have no conflict of interest to declare.

\begin{tabular}{|c|c|c|}
\hline Amn & $\mathrm{mmol} / \mathrm{L}$ & Ammonium concentration \\
\hline$A t t_{\text {eff }}$ & $\%$ & Attachment efficiency \\
\hline$E F$ & - & Expansion factor \\
\hline Glc & $\mathrm{mmol} / \mathrm{L}$ & Glucose concentration \\
\hline Lac & $\mathrm{mmol} / \mathrm{L}$ & Lactate concentration \\
\hline$N_{s 1 u}$ & rpm & $\begin{array}{l}\text { Impeller speed at which the MCs are still in contact with the } \\
\text { reactor bottom but none of the at rest (lower limit of } N_{s 1} \text { ) }\end{array}$ \\
\hline$P D L$ & - & Population doubling level \\
\hline$P / V$ & $\mathrm{~W} / \mathrm{m}^{3}$ & Specific power input \\
\hline$q A m n$ & $\mathrm{pmol} / \mathrm{cell} / \mathrm{d}$ & Specific ammonium production rate (growth-dependent) \\
\hline$q G l c$ & $\mathrm{pmol} / \mathrm{cell} / \mathrm{d}$ & Specific glucose consumption rate \\
\hline$q L a c$ & $\mathrm{pmol} / \mathrm{cell} / \mathrm{d}$ & Specific lactate production rate (growth-dependent) \\
\hline$t_{d}$ & $\mathrm{~d}$ & Doubling time of cell population \\
\hline$t_{l}$ & $\mathrm{~d}$ & Lag or cell adaption time \\
\hline$X_{A}$ & cells $/ \mathrm{cm}^{2}$ & Cell concentration on planar growth surface \\
\hline$X_{\max }$ & cells $/ \mathrm{cm}^{2}$ & Maximum cell concentration on planar growth surface \\
\hline$Y_{\text {Lac/Glc }}$ & $\mathrm{mmol} / \mathrm{mmol}$ & Lactate yield per glucose equivalent \\
\hline$\mu$ & $1 / \mathrm{d}$ & Specific cell growth rate \\
\hline$\mu_{\max }$ & $1 / \mathrm{d}$ & Maximum specific cell growth rate \\
\hline$\tau_{n t}$ & $\mathrm{mPa}$ & Local volume-weighted mean shear stress \\
\hline
\end{tabular}

\section{References}

1. Patrikoski, M.; Mannerström, B.; Miettinen, S. Perspectives for Clinical Translation of Adipose Stromal/Stem Cells. Stem Cells Int. 2019, 2019, 1-21. [CrossRef]

2. Argentati, C.; Morena, F.; Bazzucchi, M.; Armentano, I.; Emiliani, C.; Martino, S. Adipose Stem Cell Translational Applications: From Bench-to-Bedside. Int. J. Mol. Sci. 2018, 19, 3475. [CrossRef]

3. Sridhar, K.N.; Gottipamula, S.; Chokalingam, K. Major clinical application of adipose derived stem cells. J. Stem Cell Regen. Biol. 2018, 4, 4-19. [CrossRef] 
4. $\quad$ Eshukla, L.; Morrison, W.A.; Shayan, R. Adipose-Derived Stem Cells in Radiotherapy Injury: A New Frontier. Front. Surg. $2015,2,1$. [CrossRef]

5. Klar, A.S.; Zimoch, J.; Biedermann, T. Skin Tissue Engineering: Application of Adipose-Derived Stem Cells. BioMed Res. Int. 2017, 2017, 1-12. [CrossRef] [PubMed]

6. Owczarczyk-Saczonek, A.; Wociór, A.; Placek, W.; Maksymowicz, W.; Wojtkiewicz, J. The Use of Adipose-Derived Stem Cells in Selected Skin Diseases (Vitiligo, Alopecia, and Nonhealing Wounds). Stem Cells Int. 2017, 2017, 1-11. [CrossRef] [PubMed]

7. Jossen, V.; Bos, C.V.D.; Eibl, R.; Eibl, D. Manufacturing human mesenchymal stem cells at clinical scale: Process and regulatory challenges. Appl. Microbiol. Biotechnol. 2018, 102, 3981-3994. [CrossRef] [PubMed]

8. Lipsitz, Y.Y.; Milligan, W.D.; Fitzpatrick, I.; Stalmeijer, E.; Farid, S.S.; Tan, K.Y.; Smith, D.; Perry, R.; Carmen, J.; Chen, A.; et al. A roadmap for cost-of-goods planning to guide economic production of cell therapy products. Cytotherapy 2017, 19, 1383-1391. [CrossRef]

9. Solomon, J.; Csontos, L.; Clarke, D.; Bonyhadi, M.; Zylberberg, C.; Mcniece, I.; Kurtzberg, J.; Bell, R.; Deans, R. Current perspectives on the use of ancillary materials for the manufacture of cellular therapies. Cytotherapy 2016, 18, 1-12. [CrossRef]

10. Gottipamula, S.; Muttigi, M.S.; Kolkundkar, U.; Seetharam, R.N. Serum-free media for the production of human mesenchymal stromal cells: A review. Cell Prolif. 2013, 46, 608-627. [CrossRef]

11. Spees, J.L.; Gregory, C.A.; Singh, H.; Tucker, H.; Peister, A.; Lynch, P.J.; Hsu, S.-C.; Smith, J.L.P.; Prockop, D.J. Internalized Antigens Must Be Removed to Prepare Hypoimmunogenic Mesenchymal Stem Cells for Cell and Gene Therapy. Mol. Ther. 2004, 9,747-756. [CrossRef] [PubMed]

12. Fogh-Andersen, N.; Altura, M.; Altura, T.; Siggaard-Andersen, O. Composition of Interstitial Fluid. Clin. Chem. 1995, 41, 1522-1525. [CrossRef]

13. Maggs, D.G.; Jacob, R.; Rife, F.; Lange, R.; Leone, P.; During, M.J.; Tamborlane, W.V.; Sherwin, R.S. Interstitial fluid concentrations of glycerol, glucose, and amino acids in human quadricep muscle and adipose tissue. Evidence for significant lipolysis in skeletal muscle. J. Clin. Investig. 1995, 96, 370-377. [CrossRef] [PubMed]

14. Basinska, T. Adsorption studies of human serum albumin, human gamma-globulins, and human fibrinogen on the surface of p(S/PGL) microspheres. J. Biomater. Sci. Polym. Ed. 2001, 12, 1359-1371. [CrossRef] [PubMed]

15. Basinska, T. Hydrophilic Core-Shell Microspheres: A Suitable Support for Controlled Attachment of Proteins and Biomedical Diagnostics. Macromol. Biosci. 2005, 5, 1145-1168. [CrossRef]

16. Margel, S. Affinity separation with polyaldehyde microsphere beads. J. Chromatogr. A 1989, 462, 177-189. [CrossRef]

17. Lauer, S.A.; Nolan, J.P. Development and characterization of Ni-NTA-bearing microspheres. Cytometry 2002, 48, 136-145. [CrossRef]

18. Han, F.Y.; Thurecht, K.J.; Whittaker, A.K.; Smith, M.T. Bioerodable PLGA-Based Microparticles for Producing Sustained-Release Drug Formulations and Strategies for Improving Drug Loading. Front. Pharmacol. 2016, 7, 185. [CrossRef]

19. Lee, P.W.; Pokorski, J.K. Poly(lactic-co-glycolic acid) devices: Production and applications for sustained protein delivery. Wiley Interdiscip. Rev. Nanomed. Nanobiotechnol. 2018, 10, e1516. [CrossRef]

20. Tan, K.Y.; Reuveny, S.; Oh, S.K. Recent advances in serum-free microcarrier expansion of mesenchymal stromal cells: Parameters to be optimized. Biochem. Biophys. Res. Commun. 2016, 473, 769-773. [CrossRef]

21. Zhang, Z.; Eyster, T.W.; Ma, P.X. Nanostructured injectable cell microcarriers for tissue regeneration. Nanomedicine 2016, 11, 1611-1628 [CrossRef] [PubMed]

22. Jung, S.; Panchalingam, K.M.; Wuerth, R.D.; Rosenberg, L.; Behie, L.A. Large-scale production of human mesenchymal stem cells for clinical applications. Biotechnol. Appl. Biochem. 2012, 59, 106-120. [CrossRef] [PubMed]

23. Aijaz, A.; Li, M.; Smith, E.R.; Khong, D.; LeBlon, C.; Fenton, O.S.; Olabisi, R.M.; Libutti, S.; Tischfield, J.; Maus, M.V.; et al. Biomanufacturing for clinically advanced cell therapies. Nat. Biomed. Eng. 2018, 2, 362-376. [CrossRef] [PubMed]

24. Shekaran, A.; Lam, A.; Sim, E.; Jialing, L.; Jian, L.; Wen, J.T.P.; Chan, J.K.Y.; Choolani, M.; Reuveny, S.; Birch, W.; et al. Biodegradable ECM-coated PCL microcarriers support scalable human early MSC expansion and in vivo bone formation. Cytotherapy 2016, 18, 1332-1344. [CrossRef] [PubMed]

25. Kim, T.K.; Yoon, J.J.; Lee, D.S.; Park, T.G. Gas foamed open porous biodegradable polymeric microspheres. Biomaterials 2006, 27, 152-159. [CrossRef]

26. Gstraunthaler, G. Alternatives to the use of fetal bovine serum: Serum-free cell culture. ALTEX 2003, 20, $275-281$.

27. Van Der Valk, J. Fetal bovine serum (FBS): Past-present-future. ALTEX 2018, 35, 99-118. [CrossRef]

28. Tan, K.Y.; Teo, K.L.; Lim, J.F.; Chen, A.K.; Reuveny, S.; Oh, S.K. Serum-free media formulations are cell line-specific and require optimization for microcarrier culture. Cytotherapy 2015, 17, 1152-1165. [CrossRef]

29. Muñoz, M.S.; Confalonieri, D.; Walles, H.; Van Dongen, E.M.W.M.; Dandekar, G. Recombinant Collagen I Peptide Microcarriers for Cell Expansion and Their Potential Use as Cell Delivery System in a Bioreactor Model. J. Vis. Exp. 2018. [CrossRef]

30. Rafiq, Q.A.; Coopman, K.; Nienow, A.W.; Hewitt, C.J. Systematic microcarrier screening and agitated culture conditions improves human mesenchymal stem cell yield in bioreactors. Biotechnol. J. 2016, 11, 473-486. [CrossRef]

31. Yuan, Y.; Kallos, M.S.; Hunter, C.; Sen, A. Improved expansion of human bone marrow-derived mesenchymal stem cells in microcarrier-based suspension culture. J. Tissue Eng. Regen. Med. 2014, 8, 210-225. [CrossRef] [PubMed]

32. Sun, L.-Y.; Lin, S.-Z.; Li, Y.-S.; Harn, H.-J.; Chiou, T.-W. Functional Cells Cultured on Microcarriers for Use in Regenerative Medicine Research. Cell Transplant. 2011, 20, 49-62. [CrossRef] [PubMed] 
33. De Soure, A.M.; Fernandes-Platzgummer, A.; Da Silva, C.L.; Cabral, J.M.S. Scalable microcarrier-based manufacturing of mesenchymal stem/stromal cells. J. Biotechnol. 2016, 236, 88-109. [CrossRef] [PubMed]

34. Tsai, A.-C.; Jeske, R.; Chen, X.; Yuan, X.; Li, Y. Influence of Microenvironment on Mesenchymal Stem Cell Therapeutic Potency: From Planar Culture to Microcarriers. Front. Bioeng. Biotechnol. 2020, 8, 640. [CrossRef]

35. Chen, A.K.-L.; Reuveny, S.; Oh, S.K.W. Application of human mesenchymal and pluripotent stem cell microcarrier cultures in cellular therapy: Achievements and future direction. Biotechnol. Adv. 2013, 31, 1032-1046. [CrossRef]

36. Wolbank, S.; Stadler, G.; Peterbauer, A.; Gillich, A.; Karbiener, M.; Streubel, B.; Wieser, M.; Katinger, H.; Van Griensven, M.; Redl, H.; et al. Telomerase Immortalized Human Amnion- and Adipose-Derived Mesenchymal Stem Cells: Maintenance of Differentiation and Immunomodulatory Characteristics. Tissue Eng. Part A 2009, 15, 1843-1854. [CrossRef]

37. Jossen, V.; Muoio, F.; Panella, S.; Harder, Y.; Tallone, T.; Eibl, R. An Approach towards a GMP Compliant In-Vitro Expansion of Human Adipose Stem Cells for Autologous Therapies. Bioengineering 2020, 7, 77. [CrossRef]

38. Kaiser, S.C.; Jossen, V.; Schirmaier, C.; Eibl, D.; Brill, S.; Bos, C.V.D.; Eibl, R. Fluid Flow and Cell Proliferation of Mesenchymal Adipose-Derived Stem Cells in Small-Scale, Stirred, Single-Use Bioreactors. Chem. Ing. Tech. 2012, 85, 95-102. [CrossRef]

39. Jossen, V.; Eibl, R.; Kraume, M.; Eibl, D. Growth Behavior of Human Adipose Tissue-Derived Stromal/Stem Cells at Small Scale: Numerical and Experimental Investigations. Bioengineering 2018, 5, 106. [CrossRef]

40. Zwietering, T. Suspending of solid particles in liquid by agitators. Chem. Eng. Sci. 1958, 8, 244-253. [CrossRef]

41. Liepe, F.; Sperling, R.; Jembere, S. Rührwerke: Theoretische Grundlagen, Auslegung und Bewertung; Fachhochschule: Köthen, Germany, 1998.

42. Schirmaier, C.; Jossen, V.; Kaiser, S.C.; Jüngerkes, F.; Brill, S.; Safavi-Nab, A.; Siehoff, A.; Bos, C.V.D.; Eibl, D.; Eibl, R. Scale-up of adipose tissue-derived mesenchymal stem cell production in stirred single-use bioreactors under low-serum conditions. Eng. Life Sci. 2014, 14, 292-303. [CrossRef]

43. Leber, J.; Barekzai, J.; Blumenstock, M.; Pospisil, B.; Salzig, D.; Czermak, P. Microcarrier choice and bead-to-bead transfer for human mesenchymal stem cells in serum-containing and chemically defined media. Process Biochem. 2017, 59, 255-265. [CrossRef]

44. Schop, D.; Janssen, F.W.; Van Rijn, L.D.S.; Fernandes, H.; Bloem, R.M.; De Bruijn, J.D.; Van Dijkhuizen-Radersma, R. Growth, Metabolism, and Growth Inhibitors of Mesenchymal Stem Cells. Tissue Eng. Part A 2009, 15, 1877-1886. [CrossRef]

45. Higuera, G.; Schop, D.; Spitters, T.W.; Van Dijkhuizen-Radersma, R.; Bracke, M.; De Bruijn, J.D.; Martens, D.; Karperien, M.; Van Boxtel, A.; Van Blitterswijk, C.A. Patterns of Amino Acid Metabolism by Proliferating Human Mesenchymal Stem Cells. Tissue Eng. Part A 2012, 18, 654-664. [CrossRef] [PubMed]

46. Tritsch, G.; Moore, G. Spontaneous decomposition of glutamine in cell culture media. Exp. Cell Res. 1962, 28, 360-364. [CrossRef]

47. Schneider, M. The importance of ammonia in mammalian cell culture. J. Biotechnol. 1996, 46, 161-185. [CrossRef]

48. Walmsley, G.G.; Atashroo, D.A.; Maan, Z.N.; Hu, M.S.; Zielins, E.R.; Tsai, J.M.; Duscher, D.; Paik, K.; Tevlin, R.; Marecic, O.; et al. High-Throughput Screening of Surface Marker Expression on Undifferentiated and Differentiated Human Adipose-Derived Stromal Cells. Tissue Eng. Part A 2015, 21, 2281-2291. [CrossRef] [PubMed]

49. Camilleri, E.T.; Gustafson, M.P.; Dudakovic, A.; Riester, S.M.; Garces, C.G.; Paradise, C.R.; Takai, H.; Karperien, M.H.; Cool, S.M.; Im, H.-J.; et al. Identification and validation of multiple cell surface markers of clinical-grade adipose-derived mesenchymal stromal cells as novel release criteria for good manufacturing practice-compliant production. Stem Cell Res. Ther. 2016, 7, 1-16. [CrossRef] [PubMed]

50. Kapur, S.K.; Katz, A.J. Review of the adipose derived stem cell secretome. Biochimie 2013, 95, 2222-2228. [CrossRef] [PubMed]

51. Taleb, S.; Cancello, R.; Clément, K.; Lacasa, D. Cathepsin S Promotes Human Preadipocyte Differentiation: Possible Involvement of Fibronectin Degradation. Endocrinology 2006, 147, 4950-4959. [CrossRef]

52. Haywood, N.J.; Slater, T.A.; Matthews, C.J.; Wheatcroft, S.B. The insulin like growth factor and binding protein family: Novel therapeutic targets in obesity \& diabetes. Mol. Metab. 2019, 19, 86-96. [CrossRef] [PubMed]

53. Blüher, S.; Kratzsch, J.; Kiess, W. Insulin-like growth factor I, growth hormone and insulin in white adipose tissue. Best Pr. Res. Clin. Endocrinol. Metab. 2005, 19, 577-587. [CrossRef] [PubMed]

54. Wang, C.; Li, X.; Dang, H.; Liu, P.; Zhang, B.O.; Xu, F. Insulin-like growth factor 2 regulates the proliferation and differentiation of rat adipose-derived stromal cells via IGF-1R and IR. Cytotherapy 2019, 21, 619-630. [CrossRef] [PubMed]

55. Bäck, K.; Brännmark, C.; Strålfors, P.; Arnqvist, H.J. Differential effects of IGF-I, IGF-II and insulin in human preadipocytes and adipocytes-Role of insulin and IGF-I receptors. Mol. Cell. Endocrinol. 2011, 339, 130-135. [CrossRef] [PubMed]

56. Gealekman, O.; Gurav, K.; Chouinard, M.; Straubhaar, J.; Thompson, M.; Malkani, S.; Hartigan, C.; Corvera, S. Control of Adipose Tissue Expandability in Response to High Fat Diet by the Insulin-like Growth Factor-binding Protein-4. J. Biol. Chem. 2014, 289, 18327-18338. [CrossRef] [PubMed]

57. Headey, S.J.; Leeding, K.S.; Norton, R.S.; Bach, L.A. Contributions of the N- and C-terminal domains of IGF binding protein-6 to IGF binding. J. Mol. Endocrinol. 2004, 33, 377-386. [CrossRef] [PubMed]

58. Conover, C.A. Key questions and answers about pregnancy-associated plasma protein-A. Trends Endocrinol. Metab. 2012, $23,242-249$. [CrossRef]

59. Holdsworth, S.R.; Gan, P.-Y. Cytokines: Names and Numbers You Should Care About. Clin. J. Am. Soc. Nephrol. 2015, 10, 2243-2254. [CrossRef]

60. Zlotnik, A.; Yoshie, O. The Chemokine Superfamily Revisited. Immunity 2012, 36, 705-716. [CrossRef] 
61. Liu, S.; Qu, X.; Liu, F.; Wang, C. Pentraxin 3 as a Prognostic Biomarker in Patients with Systemic Inflammation or Infection. Mediat. Inflamm. 2014, 2014, 1-9. [CrossRef]

62. Liang, X.; Kanjanabuch, T.; Mao, S.-L.; Hao, C.-M.; Tang, Y.-W.; Declerck, P.J.; Hasty, A.H.; Wasserman, D.H.; Fogo, A.B.; Ma, L.-J. Plasminogen activator inhibitor-1 modulates adipocyte differentiation. Am. J. Physiol. Metab. 2006, 290, E103-E113. [CrossRef] [PubMed]

63. Kapoor, D.N.; Bhatia, A.; Kaur, R.; Sharma, R.; Kaur, G.; Dhawan, S. PLGA: A unique polymer for drug delivery. Ther. Deliv. 2015, 6, 41-58. [CrossRef] [PubMed]

64. Santoro, M.; Tatara, A.M.; Mikos, A.G. Gelatin carriers for drug and cell delivery in tissue engineering. J. Control. Release 2014, 190, 210-218. [CrossRef] [PubMed]

65. Lynn, A.; Yannas, I.; Bonfield, W. Antigenicity and immunogenicity of collagen. J. Biomed. Mater. Res. 2004, 71, 343-354. [CrossRef] [PubMed]

66. Aamodt, J.M.; Grainger, D.D. Extracellular matrix-based biomaterial scaffolds and the host response. Biomaterials 2016, 86, 68-82. [CrossRef]

67. Bonnans, C.; Chou, J.; Werb, Z. Remodelling the extracellular matrix in development and disease. Nat. Rev. Mol. Cell Biol. 2014, 15, 786-801. [CrossRef]

68. Olsen, D. Recombinant collagen and gelatin for drug delivery. Adv. Drug Deliv. Rev. 2003, 55, 1547-1567. [CrossRef]

69. Jossen, V.; Schirmer, C.; Sindi, D.M.; Eibl, R.; Kraume, M.; Pörtner, R.; Eibl, D. Theoretical and Practical Issues That Are Relevant When Scaling Up hMSC Microcarrier Production Processes. Stem Cells Int. 2016, 2016, 1-15. [CrossRef]

70. Schop, D.; Van Dijkhuizen-Radersma, R.; Borgart, E.; Janssen, F.W.; Rozemuller, H.; Prins, H.-J.; De Bruijn, J.D. Expansion of human mesenchymal stromal cells on microcarriers: Growth and metabolism. J. Tissue Eng. Regen. Med. 2010, 4, 131-140. [CrossRef]

71. Chaicharoenaudomrung, N.; Kunhorm, P.; Noisa, P. Three-dimensional cell culture systems as an in vitro platform for cancer and stem cell modeling. World J. Stem Cells 2019, 11, 1065-1083. [CrossRef] 